\title{
Los señores mayas y la recreación de episodios míticos en los programas escultóricos integrados en la arquitectura ${ }^{1}$ \\ Maya Lords and the Recreation of Mythical Episodes on Sculptural Programs Integrated in Architecture
}

\author{
Daniel Salazar Lama \\ Posgrado en Estudios Mesoamericanos, UNAM \\ Centro de Estudios Mexicanos y Centroamericanos
}

\begin{abstract}
RESUMEN: La progresiva incorporación de la figura real a los programas escultóricos integrados en la arquitectura en espacios públicos muestra la recurrente adopción de ciertas características conductuales de los dioses por parte de los gobernantes, quienes recrean ocasionalmente episodios míticos/cosmogónicos. Los casos de estudio de esta investigación, el friso de Balamkú (Campeche) y los relieves de la Gran Acrópolis Central en El Mirador (Petén, Guatemala), arrojan importante información sobre los recursos utilizados en la configuración de este tipo de escenas. Los resultados indican que, en ausencia de textos, recursos como el uso de un código visual de alto contenido simbólico y la adecuada construcción de la imagen son capaces de transmitir mensajes con sólidos trasfondos ideológicos que responden a las funciones sociales de los gobernantes.
\end{abstract}

Palabras clave: escultura integrada a la arquitectura, episodios míticos, dioses, gobernantes, ideología.

ABSTRACT: The progressive incorporation of royal potraits into sculptural programs integrated in architecture shows that rulers frequently adopted certain behavioral characteristics related to the gods by reenacting mythical/cosmological events. This study focuses on the Balamkú frieze (Campeche) and the stucco reliefs of the Great Central Acropolis in El Mirador (Petén, Guatemala). Both monuments provide important information about the compositional strategies employed in such scenes. The results suggest that in the absence of texts, the use of a visual code with a high degree of symbolic expression and the proper construction of the image are capable of conveying messages with a strong ideological backgrounds that reflect to the social functions of the Maya rulers.

KEYwORDs: sculptural programs in architecture, mythical episodes, gods, rulers, ideology.

ReCEPCIÓN: 21 de marzo de 2016.

ACEPTACIÓN: 20 de julio de 2016.

DOI: 10.19130/iifl.ecm.2017.49.797

${ }^{1}$ Una versión preliminar de este trabajo fue presentada en el XXIX Simposio de Investigaciones Arqueológicas en Guatemala (julio de 2015). 


\section{Introducción}

El presente trabajo forma parte una investigación más amplia enfocada en el análisis del sistema de representación de la figura real en los programas escultóricos integrados en la arquitectura maya de las Tierras Bajas. ${ }^{2}$ Aquí, la atención se centrará en un tipo específico de representaciones y se expondrán dos casos en los que los gobernantes se muestran recreando episodios míticos. Se trata del friso de la Estructura 1-A Sub de Balamkú, Campeche, y de los relieves de estuco de la Gran Acrópolis Central de El Mirador, en Petén, Guatemala.

Antes de iniciar el estudio es imperioso acotar y revisar algunos términos y profundizar en conceptos necesarios para analizar adecuadamente el material. Primero quiero precisar qué se entenderá por mito. Al respecto, sigo a Alfredo López Austin, ${ }^{3}$ quien entiende al mito mesoamericano como un hecho de relevancia histórica, producido por el pensamiento social e inmerso en decursos de larga duración, que consiste en creencias y narraciones enfocadas en el origen de la estructura del cosmos y de todos sus componentes en el tiempo primordial, incluyendo los seres mundanos, los dioses, las sociedades humanas y sus instituciones. Según dicho autor (López Austin, 2006: capítulo 22), el mito mesoamericano clasifica y estructura el cosmos, explica el funcionamiento del universo, cohesiona comunidades y, al ser manipulado por las élites y los grupos que ejercen el poder, legitima sistemas e instituciones.

Acorde con Jan Assman y Czaplicka (1995: 128-129) el mito refiere eventos ocurridos en un pasado distante o "tiempo profundo"; es un tipo de memoria cultural con una estructura interna dinámica, lo que explica por qué los mitos cambian en cada reproducción y se adaptan a las necesidades de quienes los controlan y repiten.

En general, el mito es protagonizado por héroes culturales o por entidades divinas. Para el caso maya, como lo especifica Christophe Helmke (2012: 92; ver también Helmke y Kupprat, en prensa; Baudez, 2004: 166-168; López Austin, 2014), es común ver a dioses y criaturas cosmológicas involucrados en estos episodios, muchos de ellos ejecutando las acciones incoativas o de creación.

Los medios de transmisión del mito pueden ser inmateriales, como el relato oral, los discursos rituales o el teatro - por mencionar algunos ejemplos-, o materiales, como las imágenes, los textos o la arquitectura. ${ }^{4}$ En las imágenes o representaciones visuales de los antiguos mayas, que podemos considerar como parte de un sistema de registro del pensamiento y de las creencias, se exploraron distintas formas de plasmar ideas mitológicas; distinción que obedece a las diversas maneras de presentar una narrativa y sus contenidos de información. Se distinguen principalmente cinco:

${ }^{2}$ Los primeros resultados de esta investigación pueden consultarse en textos previos: Salazar Lama, 2014 y 2015.

${ }^{3}$ Concepto desarrollado en el seminario "La construcción de una visión del mundo", impartido por Alfredo López Austin (enero-mayo 2012). Ver también (López Austin, 2006: 349-366).

${ }^{4}$ Para el caso mesoamericano ver López Austin, 2009 y 2014. 
1. Escenas narrativas completas o semicompletas: son las que presentan varios episodios de una misma saga mítica de forma simultánea dentro de una sola imagen y en un mismo soporte. Según Wichmann y Nielsen (en prensa), escenas como éstas muestran una serie de eventos en progreso bajo el concepto de amplia secuencialidad, "broad sequentiality", lo que produce una sucesión de situaciones con marcadas diferencias en las acciones de los personajes. Esta forma de presentar una narrativa es frecuente en los murales (ejemplo: ciclo muerte/ renacimiento del dios del maíz en la sección norte del mural poniente de la Estructura Sub-IA de San Bartolo [Saturno, 2009: 125-128; Taube et al., 2010: 72-86]) y en algunas pocas vasijas (ejemplo: vaso K3033; Chinchilla, 2011: 44; figura 11).

2. Diversos episodios de una misma narrativa presentados de forma independiente sobre distintos soportes: es el caso de algunos vasos y platos de estilo Códice con escenas pintadas que muestran diversas etapas del ciclo muerte/renacimiento del dios del maíz (García, 2011), o los diferentes capítulos del mito conocido como "La señora Dragón y el Dios Viejo" y el "Ritual del Bebé Jaguar" (García Barrios y Valencia, 2011; Valencia y García Capistrán, 2013).

3. Episodios sobresalientes de una narrativa: se trata de escenas que presentan un momento emblemático, generalmente el más elocuente y relevante para el proceso comunicativo. Según Bence Nanay (2009: 120-121) esto se debe a que una imagen puede representar más de lo que visualmente describe; es decir, son imágenes que comprimen una narrativa compleja, funcionando como instantes pars pro toto (parte por el todo) que permiten a un espectador conocedor reconstruir el mito completo (ver también Reents-Budet, 1989: 189-190) (ejemplo: escenas del dios del maíz bailando después de su renacimiento, en las vasijas del "danzante de Holmul" [Reents-Budet, 1991; Taube, 2009; Helmke y Kupprat, en prensa]).

4. Múltiples escenas independientes: en algunos casos, varios episodios pars pro toto que remiten a diferentes sagas míticas pueden ser mostrados en un mismo soporte, configurando diversas escenas que se desarrollan de forma simultánea, aunque independiente; es decir, sin una aparente conexión narrativa entre ellas (ejemplo: relieve de las "Cuatro Eras" de Toniná).

5. Elementos o íconos pars pro toto: son motivos iconográficos abstraídos de una representación visual o de un relato mítico, capaces de referir una saga entera o un episodio en concreto. Un claro ejemplo es la falda de red en el atuendo de gobernantes y personajes de élite, que remite al episodio final del ciclo mítico del dios del maíz, simbolizando fertilidad y renacimiento (ver Quenon y Le Fort, 1997: 894-898; García Barrios y Vázquez, 2011: 81-83).

En las distintas formas de representar visualmente los mitos es posible notar que los artistas mayas recurrieron a una serie de componentes para configurar la imagen, mismos que se pueden definir como las partes necesarias para construir y transmitir las ideas, y en consecuencia llamar "elementos constituyentes". Estos elementos responden a los componentes básicos de la narrativa y en las representaciones visuales son principalmente tres: las localidades donde se de- 
sarrollan los eventos, los agentes involucrados (personajes, criaturas y objetos) y las referencias gráficas a las acciones de los agentes. Las características formales de cada elemento constituyente, como los rasgos fisonómicos y el atavío de los protagonistas, corresponden a sus atributos particulares. Al respecto, es necesario considerar que la variada pluralidad de representaciones visuales de un mismo mito conlleva variaciones aspectuales, simbólicas o de identidad de los elementos que la constituyen, diferencias que obedecen a matices de significado propios de cada versión (López Austin, 2014: 167).

\section{Los casos de estudio}

Durante el Preclásico Tardío, entre los siglos iv y II a.C. aproximadamente, la imagen de los antepasados miembros de la realeza y de los gobernantes comienza a aparecer en las esculturas integradas en la arquitectura, como mascarones, frisos y relieves de estuco sobre muros y taludes; sin embargo, es hasta el Clásico Temprano (200/250-600 d.C.) cuando este tipo de representaciones se vuelve más abundante y se propaga en gran parte de las Tierras Bajas, desarrollando y consolidando un complejo sistema de representación enfocado en la exaltación y sacralización de la figura real (Salazar Lama, 2015). Dentro de este sistema, una de las formas de mostrar a los personajes reales es recreando episodios míticos y emulando las acciones de los dioses en espacios cosmológicos.

Este trabajo presenta un nuevo análisis de dos programas escultóricos integrados en la arquitectura que se enfocan en distintas figuras reales que participan en escenas y eventos de orden mítico: el friso de Balamkú, Campeche, y los tableros de estuco de la Gran Acrópolis Central de El Mirador, Petén.

\section{El friso de la Estructura 1-A Sub de Balamkú (segmento 2)}

Construido hacia finales del Clásico Temprano, a mediados del siglo vı aproximadamente, el friso de Balamkú ocupa la fachada sur de un pequeño palacio de funciones político-ceremoniales ubicado en el límite noroeste de la Plaza B del Grupo Central, y de cara a dicho espacio abierto.

La composición general del friso permite que sea seccionado en varios segmentos para su análisis (Figura 1). Los segmentos 1 al 4 están conformados por tres motivos iconográficos similares dispuestos en un arreglo compositivo vertical. Por ser los más completos, aquí se estudiarán solamente los segmentos 2 y 3.

El segmento número 2 (Figura 2) está estructurado de la siguiente forma: en la base, un amplio mascarón zoomorfo; sobre éste, una criatura zoomorfa en una postura corporal bastante peculiar; sobre sus fauces abiertas a $180^{\circ}$ se encuentra un personaje de aspecto humano sentado con las piernas cruzadas. 


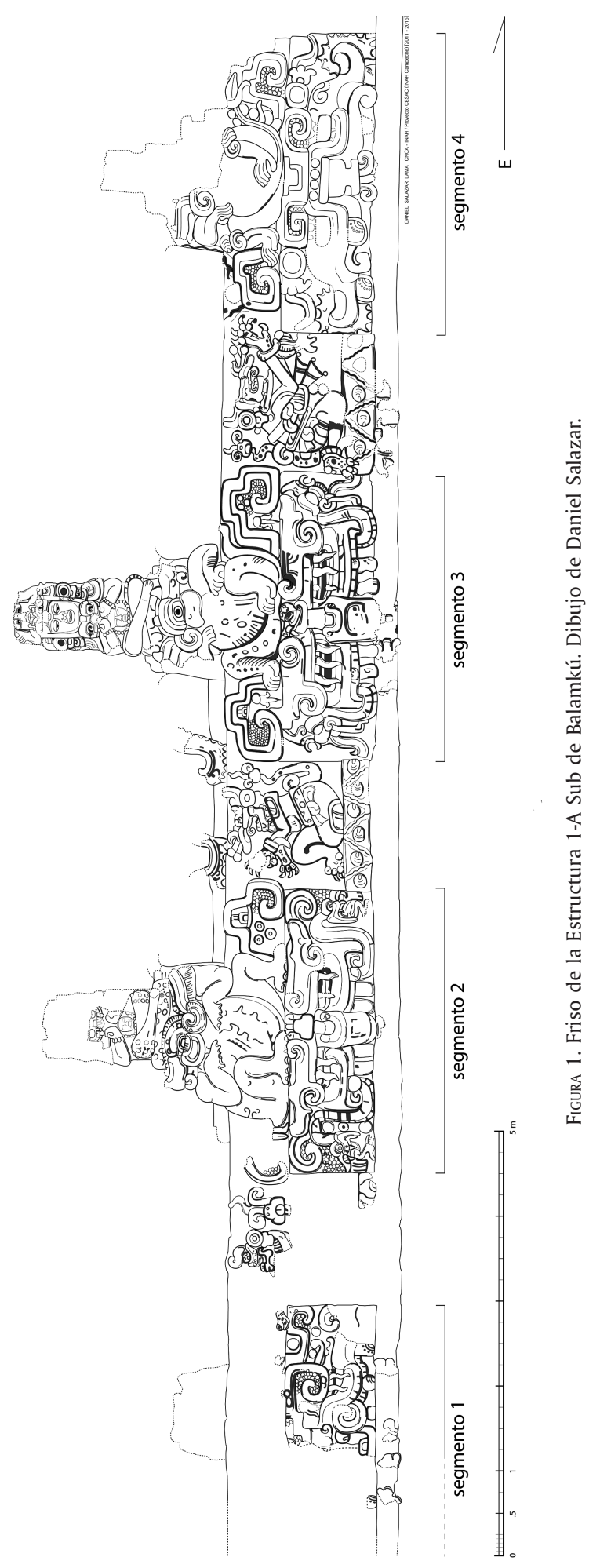




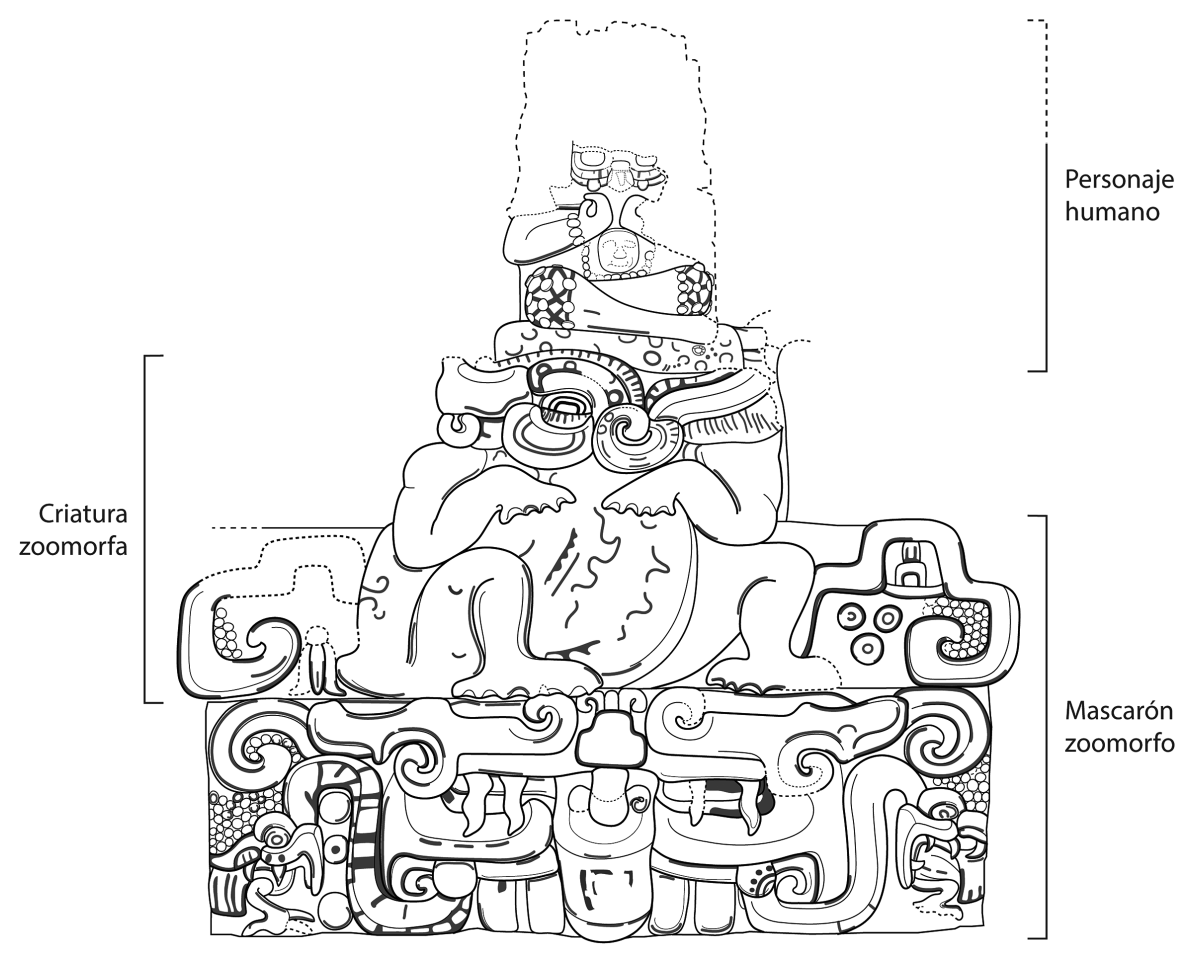

Figura 2. Segmento 2 del friso de Balamkú. Dibujo de Daniel Salazar.

El mascarón zoomorfo en la base corresponde a la figura de una montaña (witz) por sus rasgos diagnósticos. ${ }^{5}$ Su entrecejo está marcado con una versión temprana del signo T533 de posible lectura mook, "mazorca joven de maíz o espiga de maíz" (Polyukhovych, 2015). ${ }^{6}$ Por el contexto en el que se encuentra, este jeroglífico funciona como un topónimo asociado a la montaña, denominándola como "montaña de la mazorca joven de maíz" o "montaña de la espiga de maíz".

\footnotetext{
${ }^{5}$ Los rasgos diagnósticos de los mascarones witz (montaña) son tres: hendidura escalonada y terminada en volutas sobre la frente y la cabeza de un rostro zoomorfo; marcas de tun (piedra) en dientes y rostro; pestañas onduladas sobre los ojos.

${ }^{6}$ En un trabajo anterior (Salazar Lama, 2014: 67-71) sugerí una posible lectura de este topónimo como sak, "concha" (concha blanca). Sin embargo, a partir de las nuevas aportaciones de Yuriy Polyukhovych considero sumamente probable que este jeroglífico se lea como mook, aunque es difícil asegurarlo debido a que el elemento central carece de detalles pintados en el interior que lo definan con claridad. Rogelio Valencia (comunicación personal, 12 de enero de 2016) plantea que, de tratarse de la versión del Clásico Temprano del signo T533, es viable suponer que se lea MOOK o SAAK/ SAAKIL, "semilla" o "pepita" (esta última propuesta de lectura hecha por David Stuart [comunicación personal escrita con Erik Velásquez García, 24 de julio de 2015]).
} 
Dicha localidad funge como marco espacial en el que se desarrolla la acción de la escena y está caracterizada como un sitio de riqueza natural; atributo indicado por los granos de maíz que rodean al mascarón y por las serpientes que surgen de sus fauces devorando aves. En la montaña del mural norte de la Estructura Sub-IA de San Bartolo y en un vaso de procedencia desconocida (Figuras 3A y 3B), ambos componentes iconográficos señalan la fertilidad de los lugares vinculados a los ciclos míticos del dios del maíz, idea que en la montaña de la Estela 1 de Bonampak (Figura 3C) está expresada por medio de foliaciones con granos y mazorcas de maíz como la cabeza del dios.

A la flor en la frente (lado izquierdo) del mascarón witz del segmento 2 la designan como una montaña florida; localidad mítica que, según Karl Taube (2004), estuvo asociada a los procesos de regeneración del cosmos, de los dioses y de los antepasados. Por tratarse de motivos iconográficos recurrentes en muchas imágenes de montañas, considero que, más que aludir a un cerro específico, las flores en la frente de los mascarones witz refieren un atributo particular, definiéndolas como lugares aptos para el renacimiento y el ascenso.

La montaña del segmento 2 es, gracias a sus propiedades de abundancia y fertilidad, muy cercana a la "Montaña de los sustentos"; localidad que en la cosmovisión maya y de los pueblos mesoamericanos en general obtuvo varios nombres, pero cuyas características estuvieron siempre asociadas a la regeneración vegetal, al dios del maíz y a los dones otorgados a la humanidad por la deidad (López Austin y López Luján, 2009: 60-63, 100-101). Además de la evidencia iconográfica, las cualidades de esta montaña parecen estar enfatizadas por el topónimo asociado, mismo que remite a un lugar donde nace el maíz.

Emergiendo de la hendidura escalonada frontal de la montaña se halla una criatura zoomorfa que mezcla el cuerpo gordo y las extremidades palmeadas de un sapo con rasgos fisonómicos de varios reptiles y anfibios, como el maxilar superior puntiagudo de las tortugas, la barba de las "serpientes de visión” y el ojo y párpado de iguanas y tortugas. ${ }^{7}$ Es un animal idealizado, cercano en cuanto a su forma y postura a los reptiles de las Estelas 6 y 11 de Izapa (Figuras 4A y B). En la escena de la Estela 11 el reptil/anfibio abre sus fauces y sirve de conducto o vía para el nacimiento de una deidad con rasgos del dios del maíz (Guernsey, 2004: 116-117). ${ }^{8}$ Las semejanzas detectadas entre las criaturas de Balamkú e Izapa pueden indicarnos una función cosmogónica compartida: conectar distintos espacios del cosmos y permitir así la emergencia y el renacimiento de ciertos seres. En la cosmovisión maya del Clásico, este papel específico de los anfibios y reptiles se constata con las figuras en la base de la Estela N de Copán (Baudez, 2005: 58-59;

\footnotetext{
${ }^{7}$ Compárese el rostro de esta criatura con cabezas de tortugas en la cerámica maya del Clásico Temprano (ver Newman et al., 2015: figuras 3.40, 3.41 y 3.44). Incluso, la pequeña cola de la criatura del segmento 2 de Balamkú recuerda a las colas de las tortugas en las vasijas mencionadas.

${ }^{8}$ La acción de nacer de esta deidad está indicada por su postura. Según Erik Velásquez (2009: 344-349), en Mesoamérica, y sobre todo en las imágenes mayas del Preclásico y del Clásico, la postura de brazos abiertos fue utilizada como parte del lenguaje corporal de seres que están naciendo.
} 


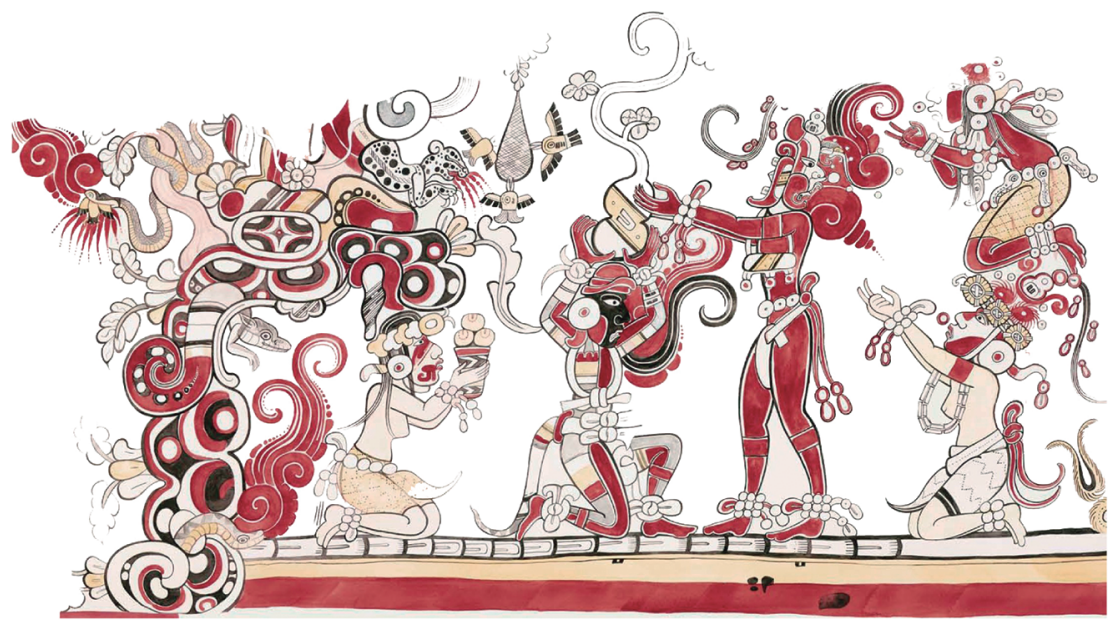

A

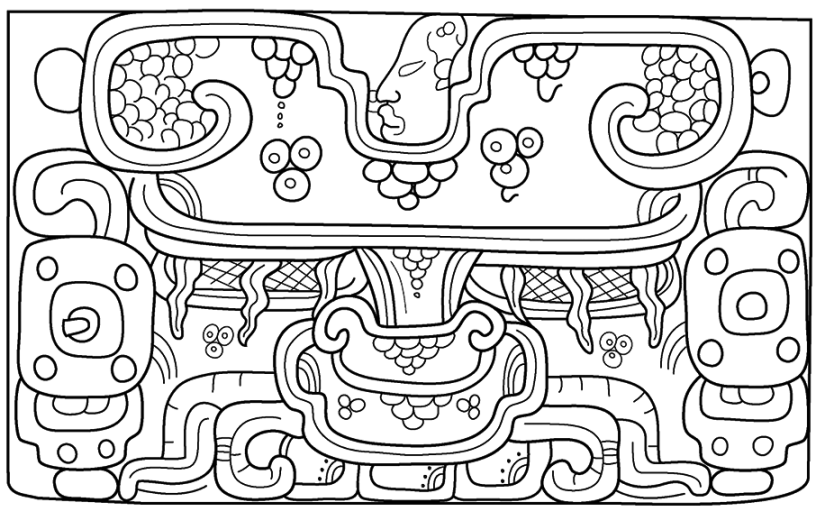

B

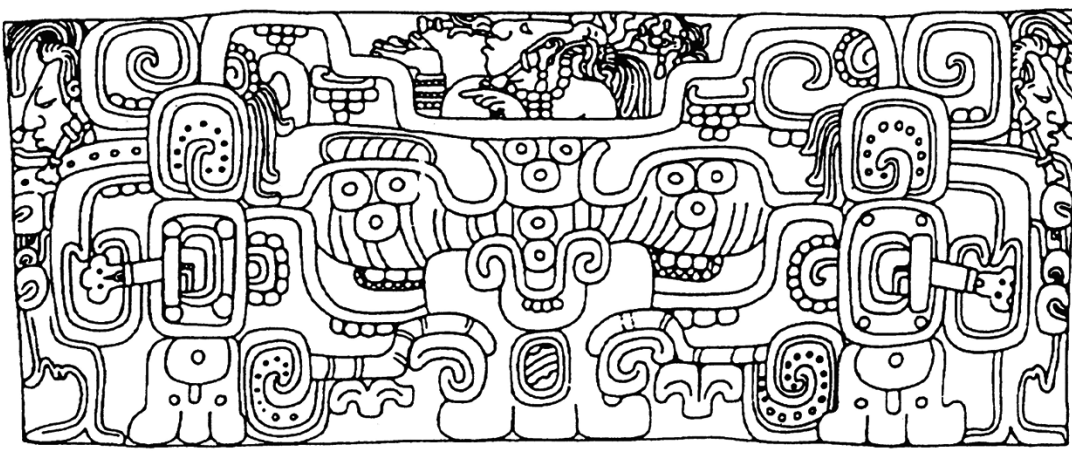

C

Figura 3. Montañas. A) Mural norte de la Estructura Sub-IA de San Bartolo. Dibujo de Heather Hurst, tomado de Saturno, Taube y Stuart, 2005; B) Detalle de vaso inciso del Clásico Temprano. Dibujo de Daniel Salazar basado en dibujo previo de Lin Crocker; C) Detalle de la Estela 1 de Bonampak. Dibujo de Peter Mathews. 
figura 2), por cuyas fauces surgen personajes humanos. En el sapo de Balamkú esta misma función se corrobora al observar que de sus fauces abiertas surge un ser humano. La interrelación que guardan ambos elementos (sapo y personaje) es un indicador de la acción que se desarrolla en la escena.
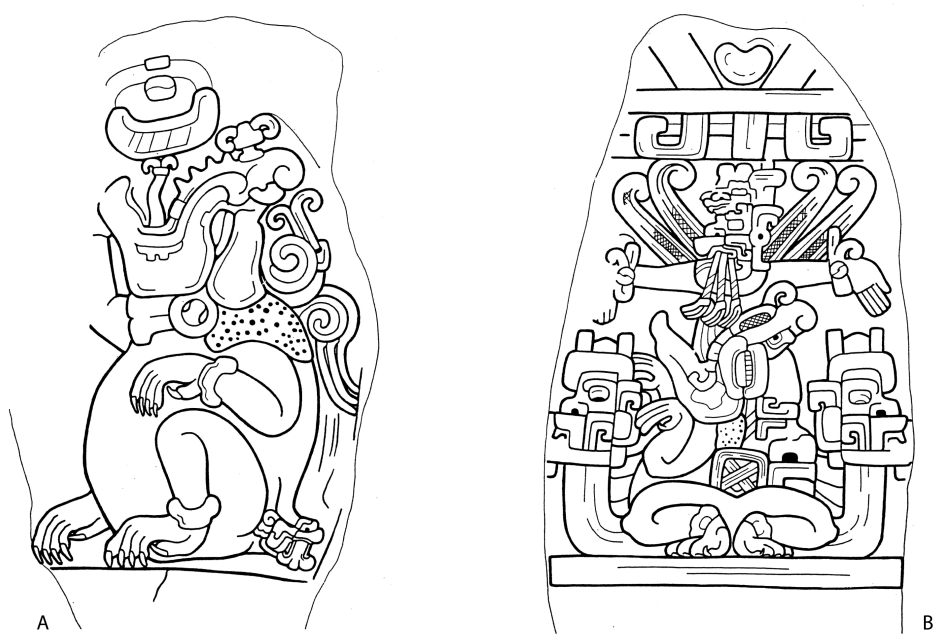

Figura 4. Estelas de Izapa. A) Estela 6; B) Estela 11. Ambos dibujos de Áyax Moreno.

El tercer elemento, el personaje humano, puede ser identificado como un gobernante a partir del cojín de piel de jaguar sobre el que se sienta — símbolo asociado con el poder real-; por las joyas que porta —indicadores de estatus social-, y por la ausencia de rasgos diagnósticos de dioses o seres sobrenaturales. Su atavío está conformado únicamente por una falda de cuentas de jade con diseño de red. Se trata de una pieza de indumentaria usada por el dios del maíz en episodios posteriores a su renacimiento (ejemplo: el danzante de Holmul; Figura 5A). En otros contextos esta falda es utilizada por gobernantes y miembros de la élite que personifican al dios del maíz o que emulan sus actos (ejemplo: Estela o Panel de Yomop; Figura 5B), a los que incluso se llega a mostrar renaciendo de manera similar, como es el caso de K'inich Janaab Pakal en la Lápida del Templo de las Inscripciones de Palenque (Figura 12A). Michel Quenon y Geneviève Le Fort (1997: 894-898) han sugerido que la falda de red opera en estos casos como una alusión al evento mítico de la resurrección [sic] de la deidad. En la escena del segmento 2 del friso, esta falda funciona de la misma manera, es decir, como un elemento pars pro toto que remite al episodio de la emergencia del dios del maíz.

El estudio del segmento 2 del friso permite reconocer una escena particularmente interesante: el surgimiento de un gobernante - posiblemente un antepasado miembro de la realeza - del interior de una montaña, acto que probable- 


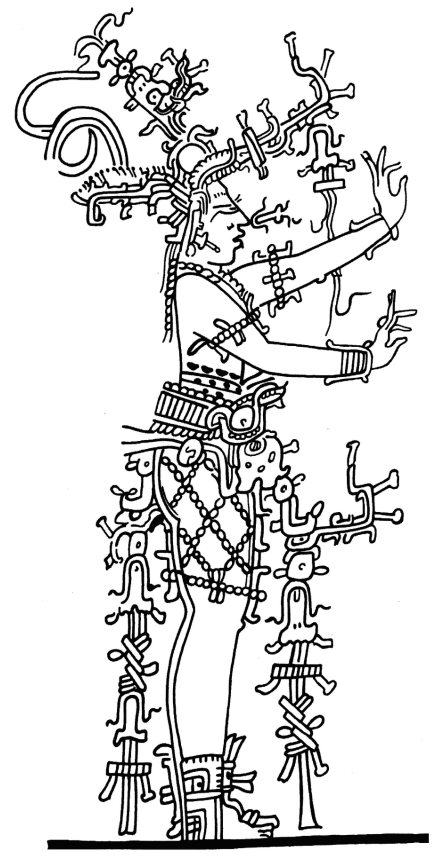

A

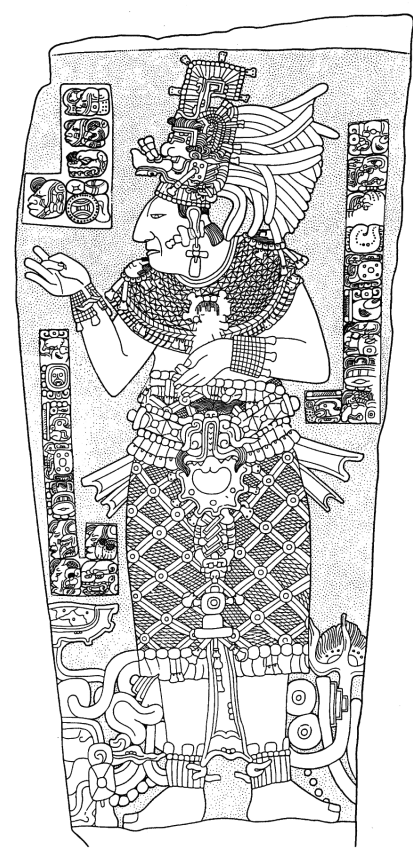

B

Figura 5. Falda de red. A) Dios del maíz en vaso de estilo Holmul. Dibujo de Oswaldo Chinchilla. Tomado de Chinchilla, 2011: Fig. 32a; B) Estela de Yomop. Dibujo de Nikolai Grube, tomado de Mayer, 1995: figura 141.

mente fue entendido como su renacimiento. ${ }^{9}$ La conjugación de los elementos constituyentes de la imagen del segmento 2 del friso y sus particulares contenidos simbólicos apuntan a que con este acto el personaje recrea el episodio mítico del renacimiento del dios del maíz. En efecto, el marco espacial de la escena de Balamkú es una montaña que comparte atributos con otras que fungen como escenarios del surgimiento del dios, y cuyo nombre subraya que se trata de una localidad donde nace la planta de maíz; a su vez, el gobernante emerge por medio de una criatura híbrida similar a la de la Estela 11 de Izapa, y porta la falda de red como una clara referencia gráfica al renacimiento de la deidad. En términos compositivos, la disposición vertical de los elementos imprime un movimiento ascendente a la imagen, dirección acorde con el surgimiento desde el interior de la montaña hacia la superficie o hacia un espacio superior/exterior. Así, la escena en su totalidad funciona como un instante pars pro toto que resume en una sola imagen un ciclo mítico complejo.

\footnotetext{
${ }^{9}$ La interpretación del personaje del segmento 2 del friso como un antepasado será discutida a profundidad más adelante.
} 
Al renacer como el dios del maíz, el personaje del segmento 2 del friso no sólo se integra al ciclo vida/muerte de la deidad, con lo que adquiere un carácter sobrehumano y sagrado, sino que también encarna ideas de abundancia y regeneración de la vida, al igual que muchos otros antepasados miembros de la realeza que se muestran emergiendo del inframundo (Martin, 2006b: 154-163).

\section{Segmento 3 del Friso de Balamkú}

El segmento 3 del friso de Balamkú (Figura 6) se ubica al este del anterior y tiene un arreglo compositivo vertical idéntico conformado por elementos parecidos.

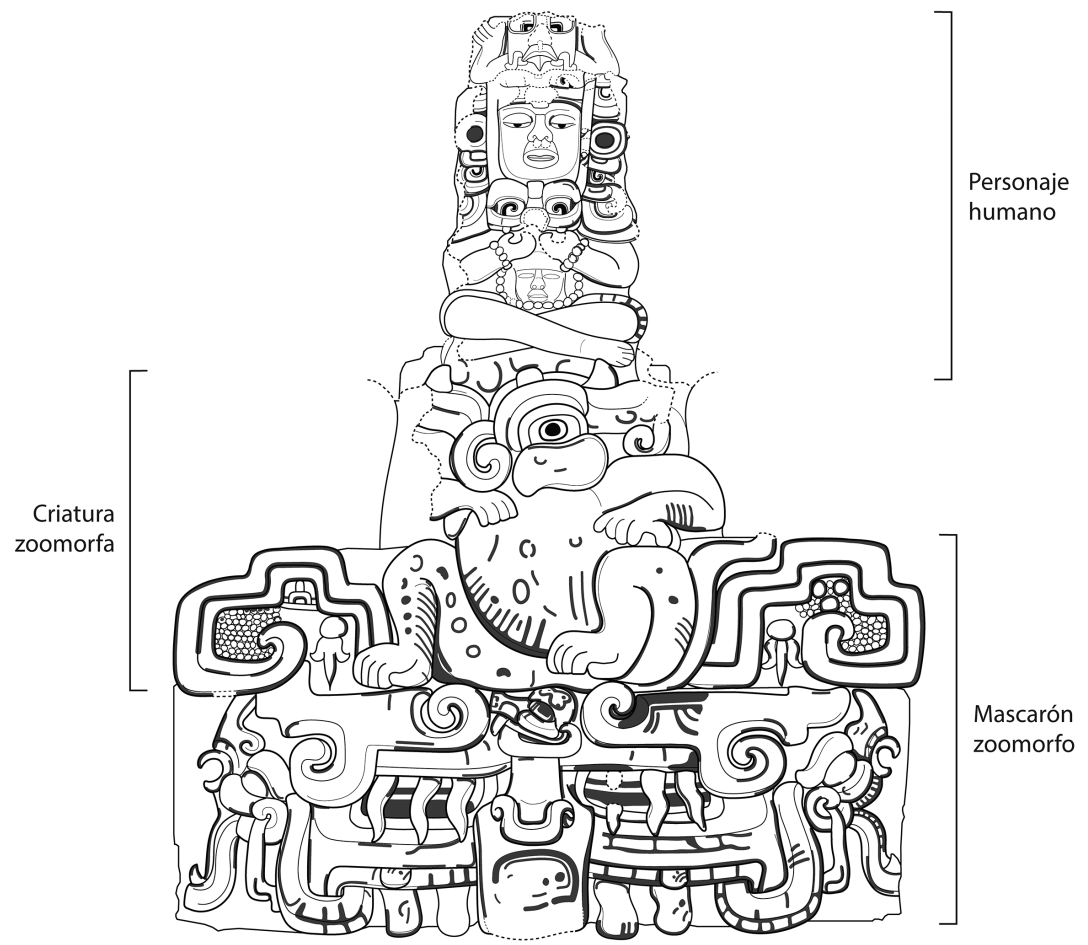

Figura 6. Segmento 3 del friso de Balamkú. Dibujo de Daniel Salazar.

El primer elemento constituyente es un mascarón witz que está marcado con un jeroglífico en el entrecejo, lo que la define como una montaña precisa dentro de la cosmovisión maya de la época. ${ }^{10}$ Este jeroglífico —que muestra la cabeza

\footnotetext{
${ }^{10}$ Una montaña con un jeroglífico nominal similar se encuentra tallada en un fragmento de una vasija de madera que posiblemente proviene de la Tumba 1 de Río Azul (Acuña, 2007: 50-53).
} 
de un pecarí con un signo K'IN infijo y una media luna debajo de las faucespodría leerse como k'ihn keken o k'ihn ahku'l ("pecarí caliente"), denominando a la montaña como la "Montaña del pecarí caliente". ${ }^{11}$

Este mascarón tiene flores en la frente que lo designan como una montaña florida. Las serpientes con las fauces abiertas a $180^{\circ}$ que emergen de la boca de esta montaña poseen rasgos formales similares a los de las sierpes de las barras ceremoniales (Figuras 7C, 7D) y las que fungen como wahyis del dios K'awiil. En dichos contextos, esos ofidios conectan los niveles del cosmos, sirviendo como medios o conductos para seres conjurados en rituales y sacrificios (Stuart, 1998: 212; Valencia Rivera y García Barrios, 2010: 241-254).

Acorde con Taube (2005: 435), las serpientes que surgen de las fauces de las montañas operan de la misma manera (Figuras 7A, 7B), definiendo a estos lugares como sitios de conjuro y ascenso de dioses y antepasados. Considero que tal es el caso de la montaña y las serpientes del segmento 3 del friso. Debido a la similitud entre las escenas de los segmentos 2 y 3 , es viable sugerir que esta característica es compartida por ambas montañas.
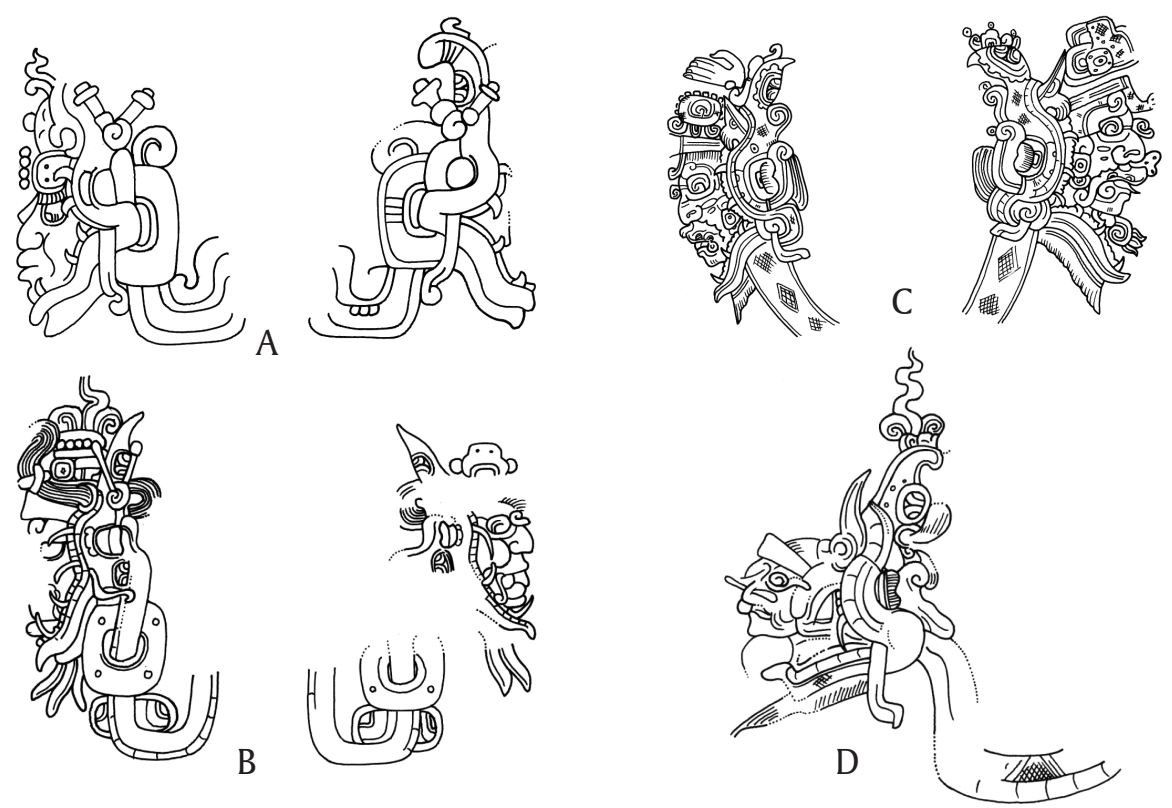

Figura 7. Serpientes en montañas y barras ceremoniales. A) Serpientes de una montaña animada de una estela de El Perú; B) Serpientes de la montaña del Monumento 106 de Toniná;

C) Serpientes de una barra ceremonial en una vasija escondite del Clásico Temprano; D) Serpiente en un extremo de barra ceremonial en el Monumento 160 de Toniná. Dibujos de Daniel Salazar.

${ }^{11}$ Según Felix Kupprat (Comunicación personal, 21 de octubre de 2015), ambos términos, keken y Ahku'l, parecen denominar a un pecarí. En este topónimo el signo K'IN funciona como un adjetivo por encontrarse al inicio de la expresión nominal; se transcribe k'ihn, y se traduce como "caliente". 
El segundo elemento constituyente del segmento 3 es una criatura zoomorfa que surge de la parte superior de la montaña y que tiene la misma postura del sapo en el segmento anterior. Se trata de un cocodrilo de vientre escamoso y abultado cuyas características formales, principalmente los colmillos prominentes, el maxilar superior saliente y curvo, la ceja o placa supraorbital, la forma de las garras y la cola, coinciden con los rasgos diagnósticos de estos reptiles en la imaginería maya (Figuras 8A-D). En la cosmovisión maya, los cocodrilos, al igual que las serpientes y los anfibios, sirven de medio material para los procesos de transformación y renacimiento de dioses y antepasados (Hellmuth, 1988: 171173). Son animales duales que pueden estar vinculados tanto al cielo como a la superficie de la tierra y a los cuerpos de agua; el cocodrilo del segmento 3 parece estar asociado a lo terrestre por su conexión con la montaña y por la ausencia de rasgos que lo vinculen con el ámbito celeste. En las obras plásticas mayas, el nexo entre el cocodrilo y el dios solar K'inich se explica como una metáfora visual que remite al levantamiento del sol desde el plano terrestre; idea expresada puntualmente en los murales de la Tumba 1 de Río Azul (Figura 8E). ${ }^{12}$

El tercer elemento es el protagonista de la escena. Es un personaje que está sentado sobre un cojín de piel de jaguar, porta un faldellín y sus joyas son similares a las del personaje del segmento 2 . Sus facciones antropomorfas y sin rasgos de deidad son un claro indicador de su naturaleza humana. Por otro lado, los motivos que rodean su rostro son comunes en retratos de soberanos en mascarones y frisos contemporáneos. En suma, estas cuatro evidencias apuntan a que se trata de un gobernante.

Las piernas cruzadas, la posición de los brazos —cruzados sobre el pecho- y las manos "ahuecadas" de este personaje son parte de un lenguaje corporal que comparte con el gobernante del segmento 2 del friso. Se trata de una pose asociada a la jerarquía y al poder, pero que también alude a un momento de transformación asociado al tránsito entre distintos espacios cosmológicos. Esta última interpretación se sustenta en escenas del dios del maíz que usa esta misma postura mientras encarna un eje cósmico ocupando un espacio liminar (ej. figurilla de jade del dios del maíz en una vasija escondrijo del Conjunto 10J-45 de Copán [Fields y Reents-Budet, 2005: catálogo 20]). En el friso de Balamkú (segmentos 2 y 3) esta particular postura corporal parece estar estrechamente vinculada con momentos de transfiguración relacionados a la emergencia de los gobernantes desde el interior de la montaña.

\footnotetext{
${ }^{12}$ Según Julia Guernsey (2002) en el arte de Izapa los motivos festonados similares al signo yax fungen como portales que propician la comunicación entre los estratos del cosmos y por ende el surgimiento de dioses y antepasados. De esta forma, podemos pensar que en el arte maya los cocodrilos y las tortugas que en su cuerpo o caparazón tienen el signo yax operan como portales para la emergencia de seres liminares, tal como aparece en algunas vasijas funerarias del Clásico Temprano (ver Newman et al., 2015: 124129). Esto puede constatarse también en los llamados "cartuchos solares", cuya forma general reproduce el diseño festonado del signo yax. Dichos cartuchos son utilizados en las imágenes relativas al ascenso celeste del dios solar K'inich y de los antepasados desde el interior de la tierra (ver Taube, 2005: 410-413).
} 

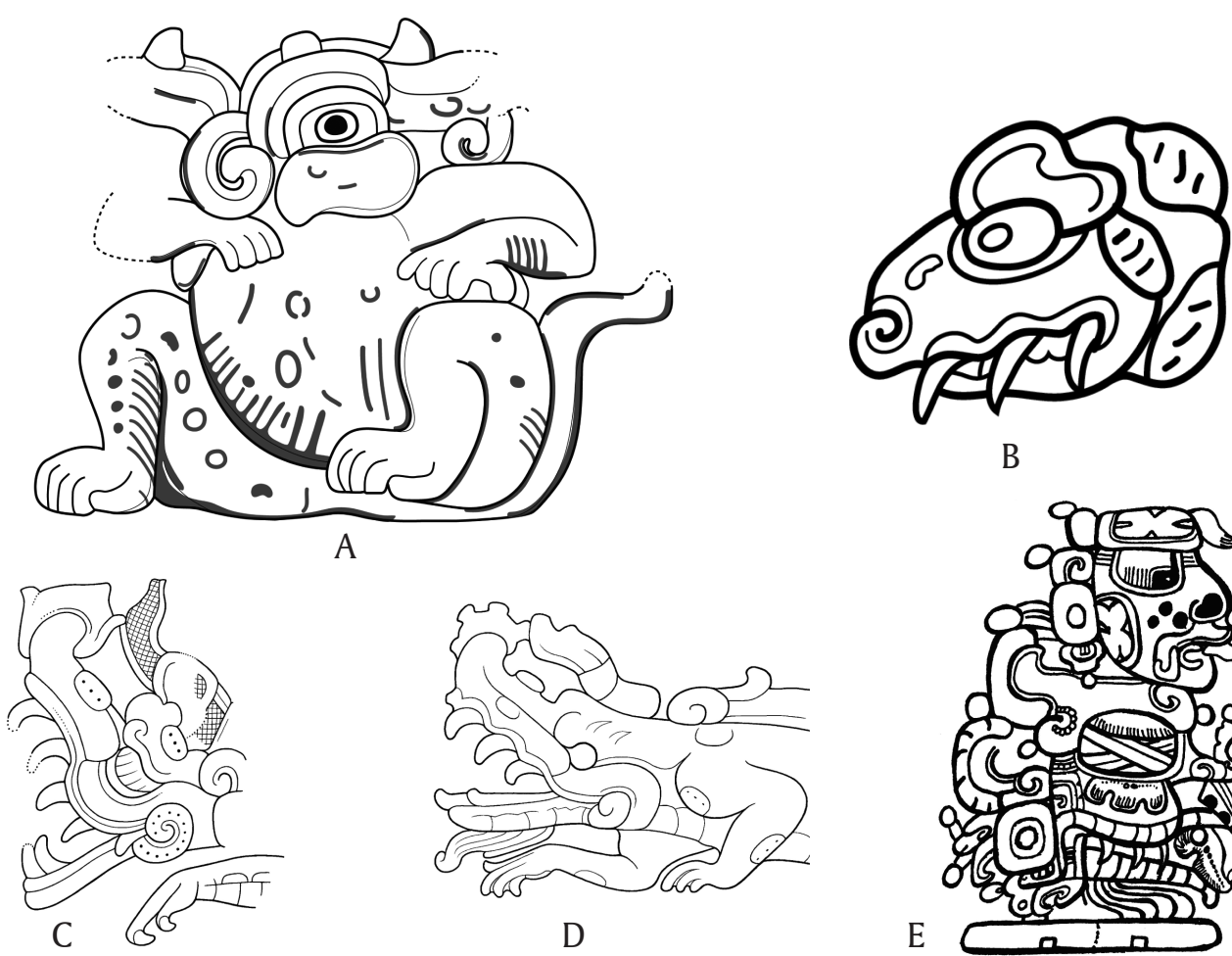

D

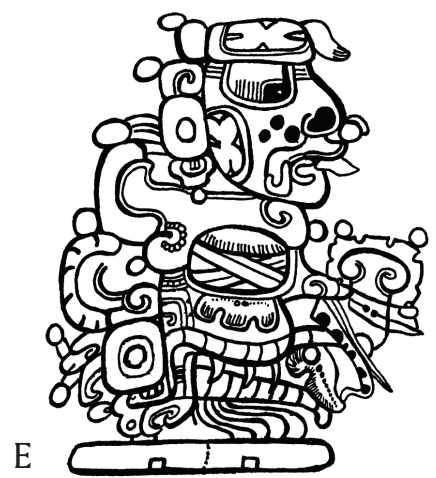

Figura 8. Figuras de cocodrilos. A) Segmento 3 del friso de Balamkú. Dibujo de Daniel Salazar; B) Detalle de la "Vasija de Tayasal". Dibujo de Daniel Salazar basado en dibujo de Sven Gronemeyer, 2010: figura 1; C) Escalinata Jeroglífica 3 de Yaxchilán. Dibujo de Simon Martin, tomado de Martin, 2006a: figura 4a; D) Detalle de concha tallada de procedencia desconocida. Dibujo de Simon Martin, tomado de Martin, 2006a: figura 4d; E) Cocodrilo y dios K'inich en el mural de la Tumba 1 de Río

Azul. Dibujo tomado de Hellmuth, 1987: figura 592.

A partir de la relación que ambos personajes guardan con las montañas —mismas que hemos definido como lugares propicios para la invocación y el ascenso-, y con base en la acción que realizan, indicada por las criaturas zoomorfas de las que emergen y por la postura corporal ligada a instantes liminares, es posible sugerir que ambos gobernantes retratados en el friso de Balamkú son en realidad antepasados reales invocados y renacidos, exhibidos en la culminación de un proceso de transformación y tránsito por el inframundo iniciado con su muerte. ${ }^{13}$

Regresando al análisis del personaje del segmento 3, vemos que su tocado (Figura 9A) está configurado por dos elementos: el rostro de K'inich al centro y un signo que Simon Martin (1997: 857; ver también Grube, 2004: 124) ha inter-

13 Ningún gobernante vivo retratado en el ejercicio de su poder tiene la mencionada postura de brazos y manos sin llevar la barra ceremonial de manera horizontal, mientras que aquellos que al mostrar tal pose no portan la barra bicéfala siempre están vinculados con procesos y momentos de transición que involucran el hecho de surgir del inframundo post mortem (ej. figurilla de jade de un personaje danzante en la Tumba 1 del Templo del jaguar, Kinichná, Dzibanché). 
pretado como un gesto de alzar o cargar (Figura 9B); un tercer elemento ubicado en la parte superior se ha perdido por completo. ${ }^{14}$ Se trata de un tocado que forma parte de la tradición de tocados que expresan gráficamente el nombre de los personajes que los portan, práctica que integra elementos de escritura en la imagen y que ha sido denominada como "asimilación pictórica" por Stone y Zender (2011: 24-25). Así, el nombre de este personaje alude al dios solar como cargador, "K'inich Cargador".
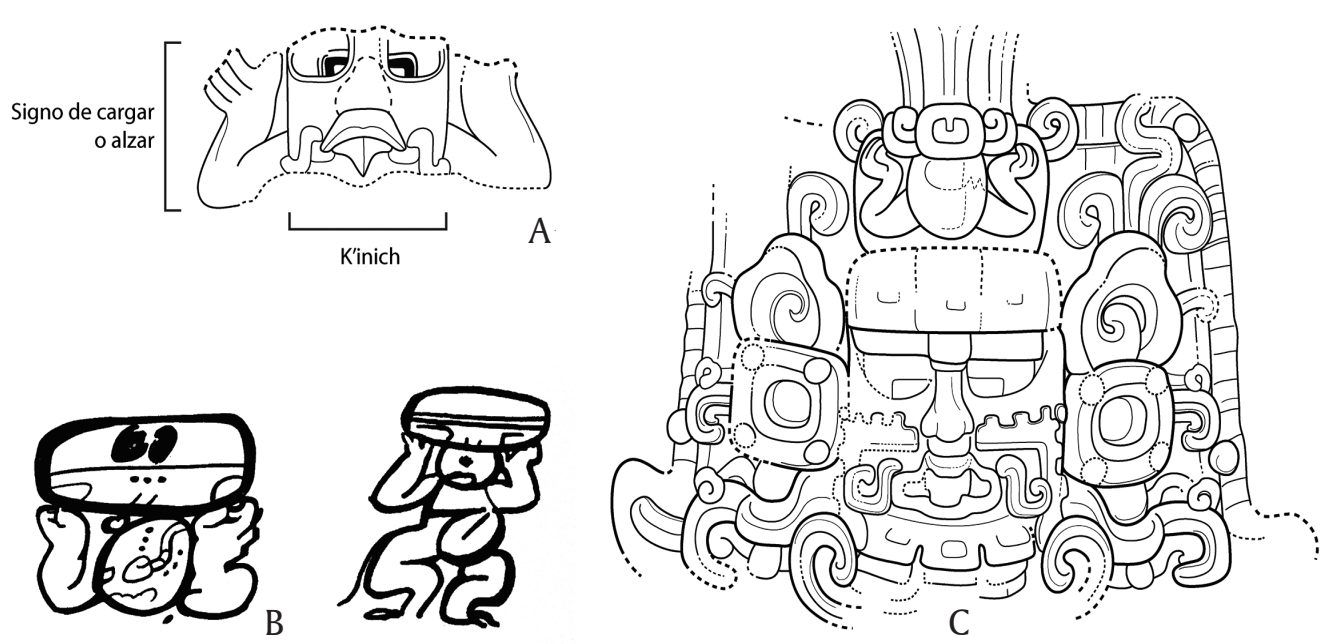

Figura 9. Nombres de dioses y gobernantes. A) Tocado del personaje del segmento 3 del friso de Balamkú. Dibujo de Daniel Salazar; B) "Cargador del Cielo". Dibujos de Nikolai Grube, 2004 : figura 6; C) Mascarón de K’inich en el Templo del Sol Nocturno de El Zotz. Dibujo de Daniel Salazar.

Pierre Colas (2003: 271) ha sugerido que en los antropónimos reales el lexema K'inich puede ser utilizado como parte de un título real (ej. K'inich Yax Ku'k $\left.\mathrm{Mo}^{\prime}\right)^{15}$ o para describir un aspecto específico del dios solar, funcionando como un "designador rígido", rigid designator, que no puede separarse de los otros elementos que conforman el nombre (ej. Sihyaj Chan K'inich). En el caso del personaje del segmento 3, la naturaleza de su antropónimo indica que el lexema K'inich fue empleado para referir una faceta o manifestación distintiva del dios solar.

\footnotetext{
${ }^{14}$ En su variante de cuerpo completo, este signo de levantar o cargar se muestra como un personaje con las piernas flexionadas y los brazos en la misma postura de levantar un objeto sobre su cabeza (ver Grube, 2004). Esta posición corporal podría estar indicando la acción a la que alude el signo (ver Figura 9B).

${ }^{15}$ Alfonso Lacadena en su conferencia "Evolución de las fórmulas reverenciales mayas asociadas a los títulos políticos de rango y cargo desde el período Clásico hasta la época colonial”, presentada en el X Congreso Internacional de Mayistas (2016), considera el término K'ihnich como una fórmula reverencial que se puede traducir como "bravo" o "fiero".
} 
En cuanto al significado del nombre del personaje de Balamkú, Nikolai Grube (2002: 324) y Pierre Colas (2014: 29-30, 40-41) plantean que los miembros de la realeza maya incorporaron frecuentemente teónimos en sus nombres personales como una estrategia de apropiación de ciertos rasgos de la identidad de un dios, como sus atributos y sus funciones. Por su parte, Ana García Barrios y sus colegas (2005: 636) formulan que en muchos casos los gobernantes usaron en sus nombres referencias a aspectos mitológicos de algunas deidades, aludiendo a su vez a un episodio mítico concreto y a una función cosmológica específica; un claro ejemplo de esta práctica sería el nombre Te K’ab Chaahk ("Chaahk Brazo de Madera o de Árbol"), utilizado por un gobernante temprano de Caracol (García Barrios, Martín y Asensio, 2005: 637). La imagen de esta manifestación del dios de la lluvia aparece en el plato K1609 del catálogo de Justin Kerr, que justamente lo muestra con la cabeza y un brazo prolongados en ramas de árbol y formando parte de una narrativa mítica más amplia.

El mascarón 3 del Templo del Sol Nocturno, en el Grupo El Diablo de El Zotz (Figura 9C), ofrece una posibilidad de entender el nombre del personaje del segmento 3 del friso de Balamkú y sus implicaciones ideológicas. Este mascarón se ubica en la fachada oriental del templo y muestra al dios solar K'inich en su aspecto diurno, ocupando el eje de una banda celeste y portando un tocado nominal con el mismo signo de los brazos en gesto de cargar (Taube y Houston, 2015: 212, 216-217). ${ }^{16}$ Se trata de un aspecto específico del dios como cargador; su naturaleza mitológica podría estar indicada en su nombre, que remite a un rol cosmológico vinculado al ámbito celestial (Salazar Lama, 2014: 130).

Muy posiblemente todo este cúmulo de ideas en torno al dios K'inich está indicado en el antropónimo del gobernante del segmento 3 del friso de Balamkú. Retomando las ideas de García Barrios y colaboradores, considero que a través de este antropónimo se establece un vínculo entre la deidad solar y un miembro de la realeza, lo que le permite a este último encarnar una faceta específica de K'inich en un momento determinado y formar parte de un ámbito sobrenatural.

En cuanto al arreglo compositivo de la escena, la disposición de los elementos constituyentes del segmento 3 reproduce un movimiento ascendente que corresponde al levantamiento del sol desde el estrato terrestre, para ser más exacto, su emergencia desde el interior de la montaña hacia un espacio superior.

\footnotetext{
16 El signo colocado sobre los brazos flexionados es la sílaba yu. Su función dentro de la expresión nominal es dudosa: es posible que se trate de la representación del elemento cargado por los brazos flexionados - en cuyo caso no funcionaría como una sílaba-, o de un complemento al signo principal (Felix Kupprat, comunicación personal, 21 de octubre de 2015).

En la Estela 4 de Uaxactún y en el Dintel 2 de Piedras Negras aparece el jeroglífico nominal "sostenedor del sol", conformado en ambos casos por el signo de los brazos flexionados, y sobre él un signo k'in (sol). Estos ejemplos sumados al tocado nominal del personaje del segmento 3 del friso de Balamkú, y junto a "Cargador del Cielo" y al tocado nominal del dios K'inich en el friso de El Zotz, indican un uso frecuente del signo de los brazos flexionados dentro de un ámbito celeste, en relación con el sol y el cielo.
} 
A pesar de no contar con una serie de imágenes con las cuales cotejar la interpretación de la escena del segmento 3 como la recreación de un acontecimiento mítico, considero que el desarrollo de la acción dentro de un marco espacial sobrenatural, la relación lógica entre el significado de cada uno de los elementos constituyentes, la forma en la que éstos se interrelacionan y el arreglo compositivo que los rige son factores que al actuar en conjunto logran comunicar visualmente una narrativa centrada en una idea concreta: la emulación por parte de un antepasado real del surgimiento y el posterior ascenso de un aspecto del dios K'inich, con quien comparte atributos y posiblemente funciones, aunque éstas no se muestran de forma explícita en la escena.

$\mathrm{Al}$ respecto, cabe señalar que la escena muestra un instante específico (el ascenso) que probablemente deriva del acto de levantar o alzar propio del dios, función y acción que estarían indicadas en el antropónimo del antepasado retratado. Es una imagen que, como plantea Nanay (2009: 120-121), representa más de lo que describe; es decir, es la imagen de un momento, "parte por el todo", de una narración mítica más amplia.

En conclusión, sugiero que se trata de una idea de orígenes míticos recreada por un miembro de la realeza, construida sobre conceptos relativos a la estructura y al funcionamiento del cosmos y al papel específico de un dios dentro de este mecanismo.

Los segmentos analizados del friso de Balamkú muestran a dos antepasados reales en lo alto de las escenas, sin señales de una jerarquía visual o compositiva existente entre ellos, característica que tal vez se repetía en las secciones del friso ahora perdidas. De forma integral, este programa escultórico pudo haber conformado una especie de "galería de antepasados", es decir, una serie de gobernantes ancestrales pertenecientes a un linaje en el poder; algo en parte equivalente a lo que se ve en el sarcófago de Pakal en el Templo de las Inscripciones, en los muros del pasillo de la Casa A del Palacio, ambos en Palenque, y en las secciones laterales del friso del Edificio Pimiento en la Acrópolis Los Árboles de Xultún (ver Saturno, Hurst y Rossi, 2012: 571-574).

En Balamkú, al presentar una serie de figuras ancestrales recreando episodios míticos bajo un esquema cosmológico se logró expresar la dimensión sobrehumana de dichos personajes y su vínculo con los dioses. Más allá de la veneración de los antepasados — práctica que sin duda se ve reflejada en el monumento-, este friso manifestó el origen sagrado de un linaje y la participación de sus miembros en los procesos de renovación del cosmos (Salazar Lama, 2014: 216-219).

\section{Los relieves de estuco de la Gran Acrópolis Central de El Mirador}

Construidos durante el Preclásico Tardío (400 a.C.-150/200 d.C.), ubicados en los márgenes de la Calzada Acrópolis y de cara a una gran plaza elevada (Carlos Morales Aguilar, comunicación personal, 17 de junio de 2015), los relieves de 
estuco de la Gran Acrópolis Central de El Mirador (Figura 10) formaron parte de un sistema hidráulico que, según Craig Argyle (2010: 540), incluyó canales para el manejo del agua y piletas utilizadas por las élites. ${ }^{17}$
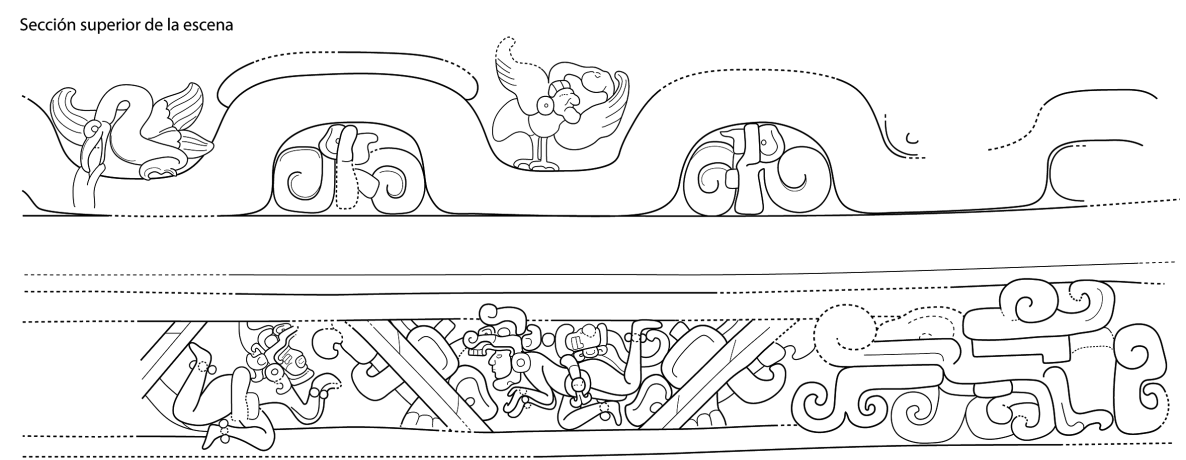

Sección inferior de la escena

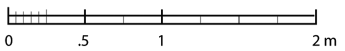

Figura 10. Relieves de la Gran Acrópolis Central de El Mirador. Dibujo de Daniel Salazar, basado en dibujo previo de Gustavo Valenzuela y en levantamiento 3D de University of South Florida, Alliance for Integrated Spatial Technologies.

La narrativa de estos relieves ha sido previamente vinculada con un episodio del Popol Vuh (ver Argyle, 2010: 540, 548; Hansen, Suyuc y Mejía, 2011: 177), ${ }^{18}$ y los protagonistas de la parte inferior identificados como Hunahpú e Xbalanqué, los héroes gemelos del relato colonial k’iche. Considero que no existen las suficientes evidencias iconográficas o algún tipo de indicio dentro del contexto que permitan conectar la escena de los relieves con los personajes referidos del Popol Vuh. Por tal razón, a continuación, se propone una nueva interpretación, resultado de un estudio sistemático que integra todas las partes que conforman la escena y de un análisis comparativo controlado. ${ }^{19}$

${ }^{17}$ En una etapa arquitectónica posterior se construye la Estructura 3D2-6, ubicada al norte del programa escultórico. Sin duda esto restringió la visibilidad que se tenía de los relieves de estuco desde la plaza elevada.

18 Argyle interpreta las imágenes en estos relieves de la siguiente forma: "La escena en el panel más abajo probablemente representa a los Héroes Gemelos del Popol Vuh, nadando en el mundo sobrenatural y llevan la cabeza de su padre al lugar donde él será resucitado como el dios del Maíz" (Argyle, 2010: 540).

${ }^{19}$ Es necesario mencionar que recientemente fueron descubiertos otros elementos de estuco en relieve debajo del programa escultórico de la Calzada Acrópolis (Hansen, 2012). Incluye cabezas zoomorfas y un fragmento de mascarón en el extremo derecho (ver Hansen, 2012, Fig. 8.1-8.4). Al momento se desconoce la configuración total del programa escultórico, ya que algunas partes de los nuevos relieves se encuentran gravemente dañadas o mutiladas; por lo que he decidido únicamente tratar las secciones mejor conservadas y que permiten un estudio a profundidad. 
La escena está separada en dos largas secciones. La superior muestra una banda ondulante que representa un flujo de agua con dos aves acuáticas (y un posible pez) y, en la parte inferior de esta banda, dos rizos de nubes fusionados con el rostro de Chaahk, mismo que se presenta de manera esquemática por medio de un labio superior prominente, una nariz y un único diente puntiagudo (Doyle y Houston, 2012). ${ }^{20}$ En conjunto, estos elementos reproducen un ambiente generado y dinamizado por el dios de la lluvia.

La sección inferior muestra dos cabezas de serpientes estilizadas en posición diagonal. En otros monumentos e imágenes contemporáneas, como algunos monumentos de Izapa, Takalik Abaj y Kaminaljuyú, y en las Tierras Bajas, el friso de la Estructura Sub II C1 de Calakmul, y el mural poniente de San Bartolo (Figuras 11A-B y 16A), cabezas de serpientes similares se unen a los extremos de bandas celestes para configurar la representación del cielo (Quirarte, 1974: 130; Taube, 1995: 91-94; Taube et al., 2010: 48-49). Además, en un examen detallado de estas cabezas en los relieves de El Mirador se notará que su particular posición se corresponde con las franjas diagonales que forman parte de las bandas celestes en las estelas de Izapa y en el friso de Calakmul (Figuras 4B y 16A). Así, dichas cabezas de serpientes son elementos pars pro toto que definen el cielo como marco espacial en el que se integran los personajes y se desarrolla la acción.

En el extremo derecho de la sección inferior e incorporado parcialmente a la banda celeste, se encuentra una cabeza de reptil en gran medida similar a los cocodrilos de las Esculturas 2 y 5 de Kaminaljuyú (Figura 11C). ${ }^{21}$ Tiene un ojo en forma de "L" propio de seres celestes y un rizo de nube en la parte posterior de su cabeza. Por su particular ubicación y los detalles de su rostro es posible que se trate de un antecedente de los lagartos estelares en algunos monumentos del Clásico, vinculado en esta escena al ciclo pluvial.

Los protagonistas son dos figuras antropomorfas en actitud descendente y con los brazos y las piernas flexionadas, postura que indica la acción en la escena y que ha sido interpretada como el acto de nadar o de reptar (Argyle, 2007: 548; Doyle y Houston 2012). Un análisis comparativo más preciso muestra que dicha postura corporal se presenta a menudo en personajes inmersos en medios acuáticos, aunque no es privativa de quienes ocupan de forma transitoria estos ambientes. Por ejemplo, como se muestra en la Figura 12C, ésta pose forma parte del lenguaje corporal de dos dioses que en el friso del Palacio H Sub-2 de Uaxactún transitan entre distintos espacios cosmológicos; en este caso, el descenso celestial hacia un

20 Doyle y Houston (2012) plantean que el rostro de Chaahk, mostrado de manera arcaica, casi en estilo olmeca, está integrado a un motivo de doble voluta, semejante al signo muyal (nube) de la escritura del Clásico (ver también Stone y Zender, 2011: 142-143).

21 El maxilar superior prominente y enroscado en la punta, las cejas con volutas y una prolongación en su extremo, y los apéndices bífidos en las comisuras de las fauces son rasgos comunes en los cocodrilos del período Clásico y en los monumentos preclásicos de sitios como Kaminaljuyú (Estela 5) e Izapa (Estelas 25 y 27). 

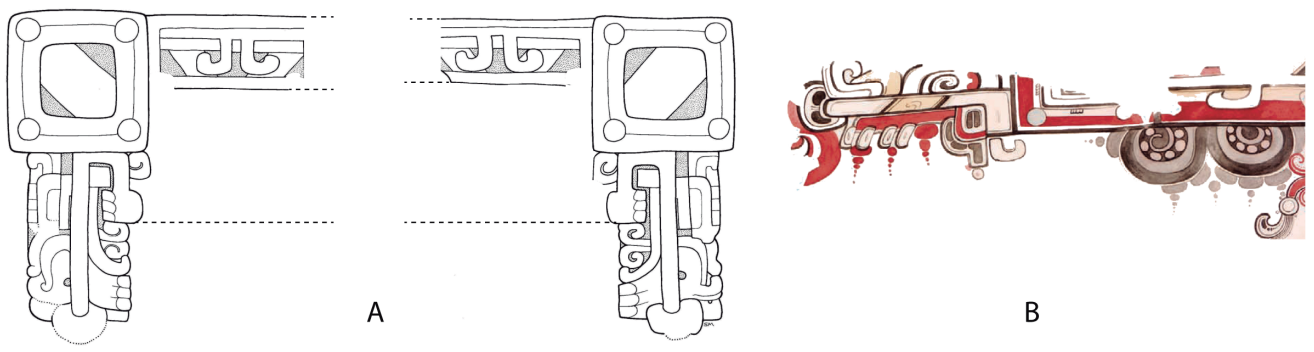

B

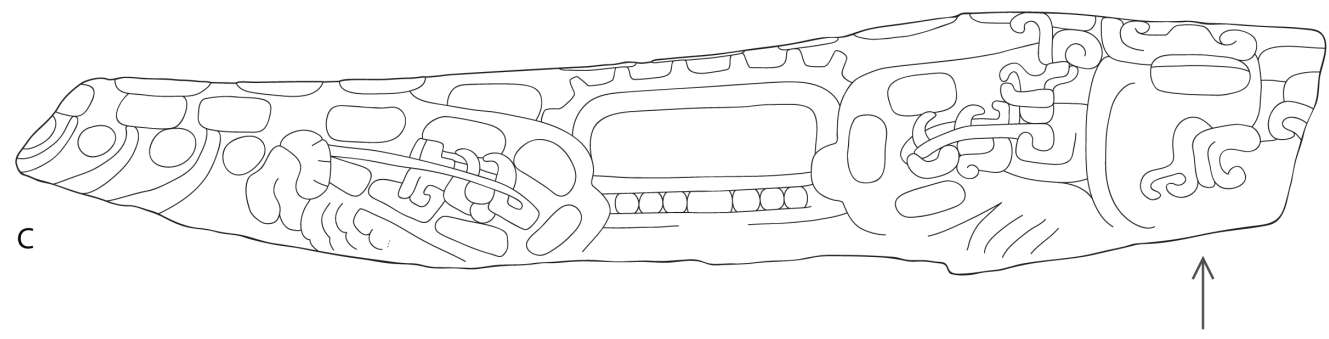

FiguRA 11. Cabezas de serpiente en bandas celestes y cocodrilo. A) Detalle del friso de la Estructura

Sub II C1 de Calakmul. Dibujo de Simon Martin, tomado de García Barrios, 2009: figura 1.14a;

B) Detalle de mural poniente de Estructura Sub-IA de San Bartolo. Dibujo de Heather Hurst, tomado de Taube et al., 2010: figura 61; C) Escultura 2 de Kaminaljuyú. Dibujo de Lucia Henderson, cortesía de la autora. La flecha señala la cabeza del cocodrilo en el monumento de Kaminaljuyú.

estrato inferior. ${ }^{22}$ Se trata de una pose parecida a la postura de nacimiento con la que aparece K'inich Janaab Pakal en la lápida del Templo de las Inscripciones de Palenque (Figura 12A), en una escena que muestra su surgimiento del inframundo; y similar a la pose del dios del maíz infante que renace de un espacio acuático en un vaso estilo Códice (Figura 12B). En todos los casos, dicha postura de brazos y piernas flexionados alude a un estado liminar y al tránsito entre distintos espacios, mientras la orientación del cuerpo indica si éste asciende o desciende. ${ }^{23}$

La figura de la izquierda tiene un ojo de contorno angular característico de dioses celestes y otros seres que habitan el ámbito celestial, mientras que el personaje central posee rasgos enteramente antropomorfos y presenta las características formales y algunos elementos del atavío propios de los gobernantes durante el Preclásico Tardío en sitios como San Bartolo, Uaxactún o Kaminaljuyú (Figuras 13A-B). Entre los muchos rasgos físicos que nuestro personaje central

${ }^{22}$ Es una pose generalmente vinculada al nacimiento y a la materialización de seres por medio del conjuro y el sacrificio. Sin embargo, en el mural poniente de la Estructura Sub-IA de San Bartolo se muestra un dios del maíz con la misma postura descendiendo por una corriente de agua, lo que se ha interpretado como su muerte (Taube et al., 2010: 84).

${ }^{23}$ Concuerdo con Velásquez García (2009: 343) cuando sugiere que esta pose conlleva cierto grado de ambigüiedad, y considero que será el contexto el que determine su significado de forma certera (ver también Martin, 2002: 53-56). 


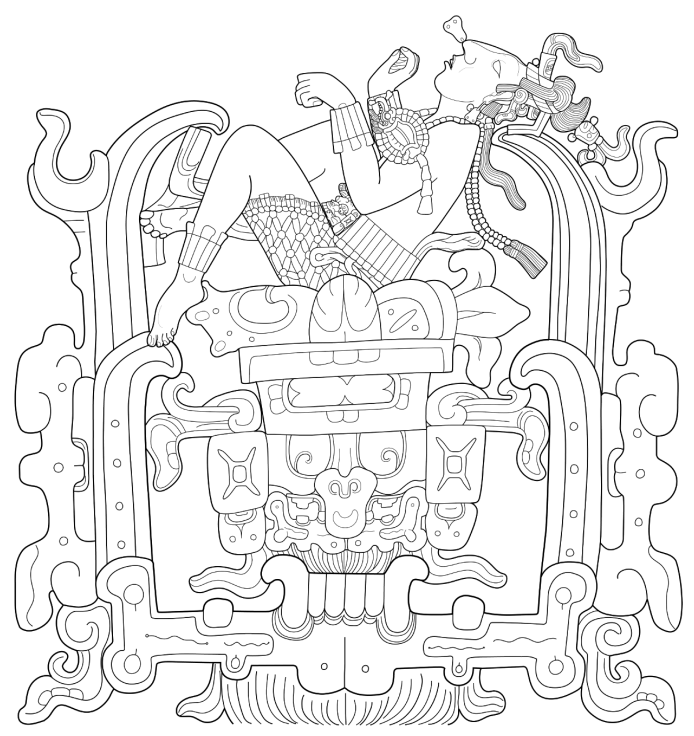

A

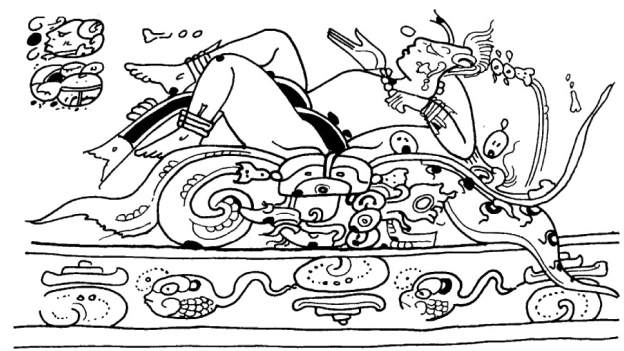

B

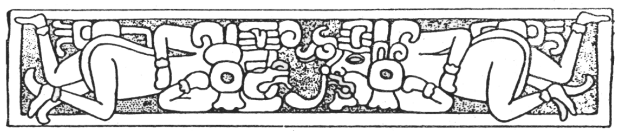

C

Figura 12. A) Detalle de lápida del Templo de las Inscripciones, Palenque. Dibujo de Daniel Salazar; B) Detalle de vaso estilo Códice de Calakmul. Dibujo de Karl Taube, tomado de Taube et al, 2010: figura 45B; C) Detalle del friso del Palacio H Sub-10, Uaxactún. Dibujo de Paulino Morales, tomado de Valdés, 1989: figura 3.

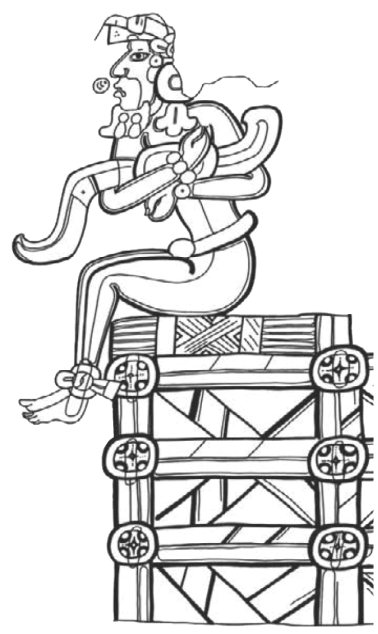

A

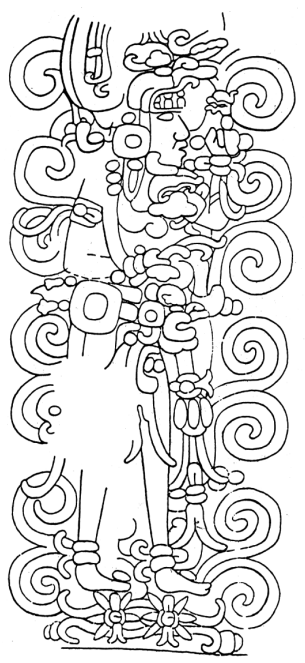

B

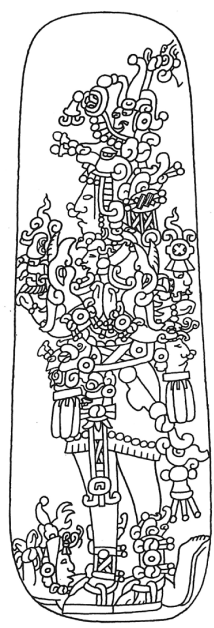

C

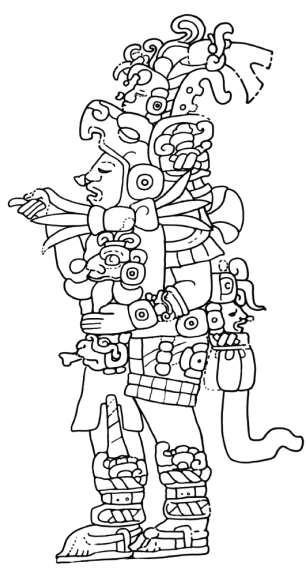

D

FIGURA 13. Imágenes de gobernantes tempranos. A) Detalle del mural poniente de la Estructura

Sub-IA de San Bartolo. Dibujo de Heather Hurst, tomado de Taube et al., 2010: Fig. 39B;

B) Relieve de la Estructura H Sub-10 de Uaxactún. Dibujo tomado de Valdés, 1989: figura 11;

C) “Celta de Leiden”. Dibujo de J. Montgomery, tomado de www.famsi.org; D) Relieve de San Diego.

Dibujo de Linda Schele, tomado de www.famsi.org 
comparte con estos gobernantes tempranos resaltan el cuerpo y el rostro estilizados, las extremidades delgadas y las manos y los pies solucionados de manera esquemática, mientras que su atavío se reduce a un cinturón de tela anudada, orejeras circulares, joyas de cuentas de jade, y una cabeza antropomorfa en la parte posterior del cinturón. En conclusión, el análisis comparativo indica que la figura central de los relieves de El Mirador está siendo mostrada a la usanza de los soberanos contemporáneos, por lo que es viable identificarlo como un gobernante.

James Doyle y Stephen Houston (2012) han notado que ambos personajes llevan tocados y orejeras de conchas seccionadas; el tocado del personaje central tiene además una mandíbula descarnada a manera de barbijo. Por medio de un estudio comparativo con ejemplos estrictamente contemporáneos, dichos autores (Doyle y Houston, 2012: figura 2) lograron identificar este último tocado como una variante de la cabeza del dios Chaahk. Partiendo de sus propuestas, sugiero que tal reconocimiento se puede igualmente obtener tomando en cuenta los siguientes rasgos diagnósticos (ver Figura 14): voluta sobre la cabeza y la frente, que en algunos casos posiblemente se trate de cabello anudado [a]; labio superior prominente y proyectado hacia el frente (que a veces termina en voluta) [b], y un maxilar inferior parecido al de ciertos ejemplos del dios durante el Preclásico y el Clásico Temprano [c] (ver García Barrios, 2009: figuras 1.17-1.25). Al usar este tocado el gobernante se muestra personificando al dios en un momento específico.

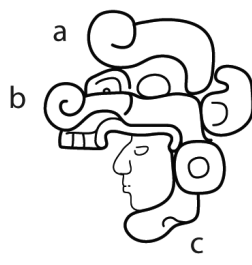

A

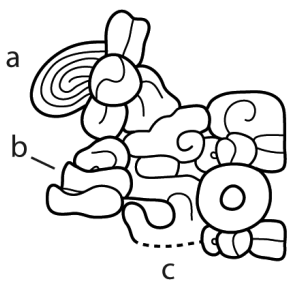

B

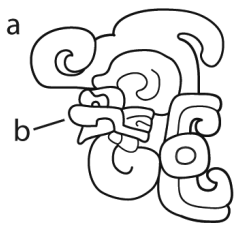

C

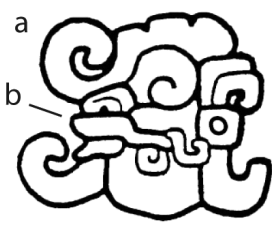

D

Figura 14. Rasgos de Chaahk durante el Preclásico. A) Tocado del personaje central de los relieves de El Mirador. Dibujo de Daniel Salazar; B) Friso de Calakmul. Dibujo de Daniel Salazar, basado en dibujo previo de Simon Martin; C) Estela 4 de Kaminaljuyú. Dibujo de Daniel Salazar; D) Estela 1 de Izapa. Dibujo de Áyax Moreno. Rasgos señalados en la imagen: [a] rizo sobre cabeza y frente;

[b] labio superior prominente; [c] maxilar inferior descarnado.

El segundo personaje, ubicado en el extremo izquierdo de la escena, tiene rasgos fisonómicos idénticos a los de la cabeza efigie que porta el personaje central en la parte posterior: rostro antropomorfo, ojo angular en forma de "L" acostada y un elemento circular sobre la boca. ${ }^{24}$

\footnotetext{
${ }^{24}$ Como lo sugieren Doyle y Houston (2012), es posible que el tocado de este segundo personaje sea otra variante del dios Chaahk.
} 
Si se toma en cuenta que hacia inicios del Clásico Temprano y durante todo ese período los gobernantes mayas se mostraban portando las cabezas de sus antepasados en la parte trasera de los cinturones (Houston y Stuart, 1998: 85), siendo algunas de las primeras imágenes los soberanos retratados en la "Celta de Leiden" y en el relieve de San Diego, Petén (Figura 13C-D), es posible sugerir que la cabeza efigie que lleva el gobernante de los relieves de El Mirador, que por cierto ocupa una posición similar, representa a un antepasado. ${ }^{25}$

Al mostrarse con los mismos rasgos fisonómicos, ¿el segundo personaje de la escena también sería un antepasado? He preferido dejar esta interpretación abierta, ya que la considero sumamente tentativa. Sin embargo, sí es viable suponer que este segundo personaje de la escena forme parte activa de la narrativa, tal vez personificando, al igual que el personaje central, a una variante del dios Chaahk por medio del uso de un tocado.

La personificación de deidades y seres sobrenaturales fue una práctica común entre los soberanos mayas. Muchos investigadores (Stone, 1991: 194; Houston, Stuart y Taube, 2006: 270-279; Knub, Thun y Helmke, 2009: 180) la reconocen como un instante de concurrencia entre seres de distintas naturalezas y esencias; es decir, la manifestación de un dios o ente sagrado a través de un agente humano, quien momentáneamente adquiere las capacidades y los atributos característicos del ser que encarna. Al igual que en los relieves de El Mirador, en las imágenes del Preclásico y del Clásico, tanto de las Tierras Bajas como de los sitios de la costa del Pacífico, esta práctica se expresó por medio del uso de máscaras y tocados (ejemplo: Estela 11 de Kaminaljuyú y Estela 4 de Izapa). Particularmente interesante para nuestro estudio es el mazo de piedra resguardado en el Museo de Historia de Tenosique, Tabasco (Figura 15), estilísticamente atribuido a los inicios del período Clásico Temprano (Polyukhovych y Tunesi, 2012: 99). El relieve muestra en una primera escena la imagen de un ajaw sosteniendo con su mano izquierda un tocado/máscara del dios Chaahk. La siguiente escena presenta, como lo sugieren Polyukhovych y Tunesi (id.), al mismo señor con el tocado puesto y en un acto de personificación del dios, con lo que adquiere algunos de sus rasgos físicos (piel de reptil) y sus características conductuales (blandir un hacha).

La comprensión de la compleja escena de los relieves de El Mirador se puede lograr a través de un estudio comparativo con monumentos relativamente contemporáneos. El friso de la Estructura Sub II C1 de Calakmul y la Estela 23 de Izapa (Figuras 16A-B) poseen elementos constituyentes similares y en parte cercanos a lo que se observa en El Mirador. En efecto, ambos monumentos muestran a un dios Chaahk descendente con la misma postura de brazos y piernas flexionados, rodeado de un espacio celestial solucionado con motivos iconográficos parecidos

\footnotetext{
${ }^{25}$ Desde el Preclásico los antepasados pueden presentarse con rasgos solares o de entidades celestes, como en este caso el ojo en forma de "L", característico del dios K'inich del Preclásico. Figuras de antepasados con elementos solares o celestiales pueden verse en la Estela 2 de Takalik Abaj y la Estela 31 de Tikal.
} 

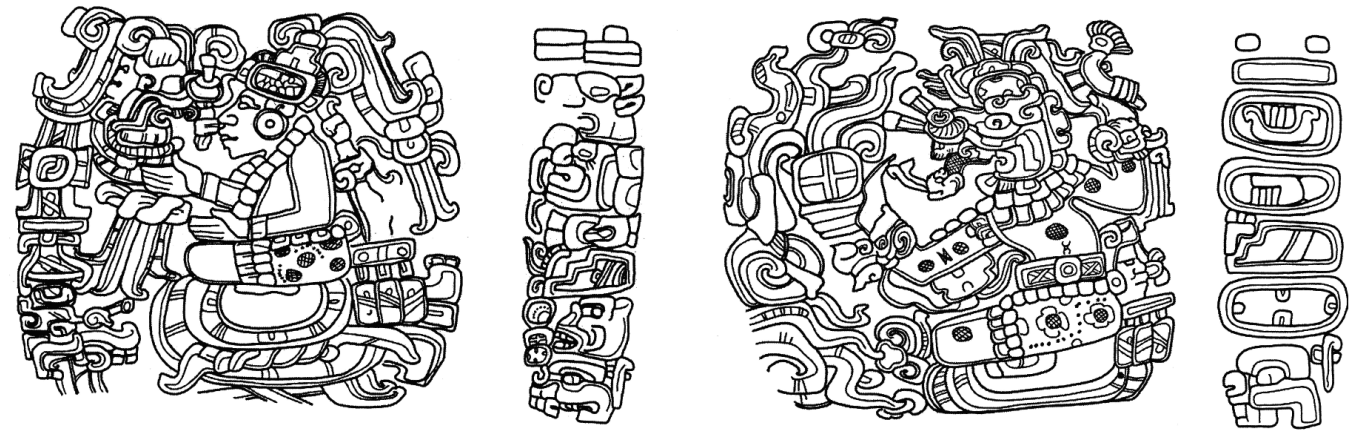

Figura 15. Escena de personificación. Relieve del Mazo de Piedra de Tenosique. Dibujo de Raphael Tunesi, tomado de Polyukhovych y Tunesi (2012: figura 4).

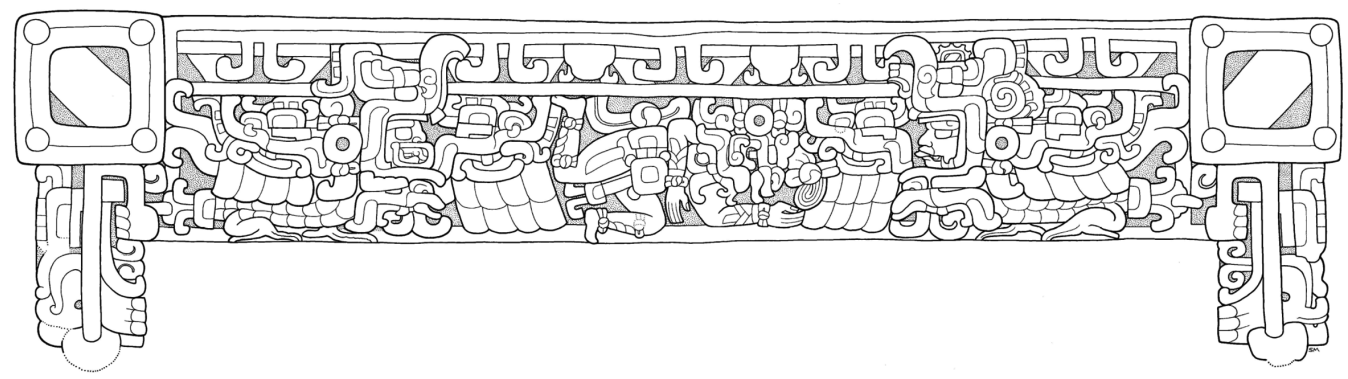

A

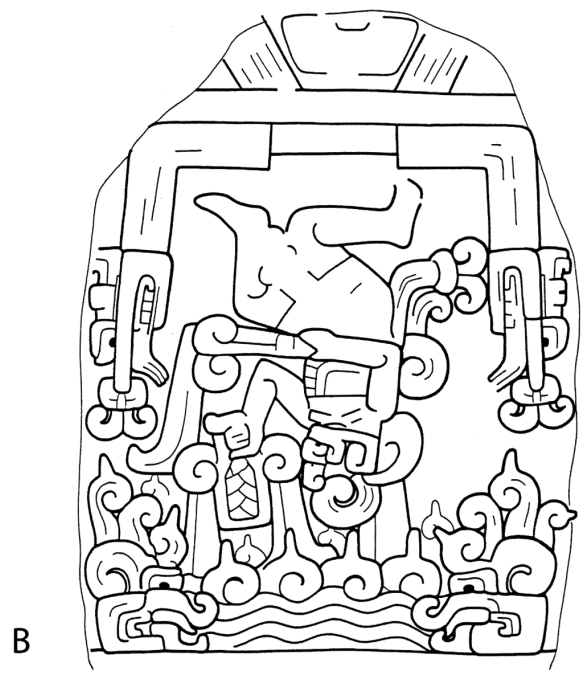

Figura 16. Monumentos del Preclásico con Chaahk descendente.

A) Friso de la Estructura Sub II C1 de Calakmul. Dibujo de Simon Martin, tomado de García Barrios, 2009: Fig. 1.14a;

B) Estela 23 de Izapa. Dibujo de Áyax Moreno 
y con referencias a los niveles inferiores del cosmos en la base de las escenas. ${ }^{26}$ Las marcadas similitudes de ambos monumentos son suficientes para evidenciar que se trata de un mismo episodio: el descenso de Chaahk desde el cielo hacia un nivel inferior del cosmos.

Debido a su carácter cosmológico y por mostrar una misma deidad realizando un acto determinado, sugiero que dicho episodio es de orden mítico; a su vez, la naturaleza progresiva de las escenas, que muestra un momento dentro del desarrollo de un proceso, apunta a que ambas describen un instante pars pro toto de una idea o ciclo mítico más amplio.

Construida a partir de los mismos elementos constituyentes y recursos compositivos parecidos, y en especial, al describir una misma acción e incluir referencias gráficas al dios Chaahk, la escena de los relieves de El Mirador sería una reproducción del episodio mítico visto en el friso de Calakmul y en la estela de Izapa; la gran diferencia radica en la sustitución del dios por un gobernante que lo personifica.

Como se mencionó, en el contexto espacial de los relieves de la Gran Acrópolis Central se integraron canales para el manejo del agua y piletas o reservorios para su almacenamiento y uso por parte de los grupos de élite; todo de frente a una plaza elevada de posible carácter público, desde donde los relieves eran perfectamente visibles (Carlos Morales Aguilar, comunicación personal, junio 2015). Edgar Suyuc y Richard Hansen (2015) han sugerido que los canales que encausaban el agua hacia los reservorios — probablemente construidos en una etapa arquitectónica posterior- pasaban justo por debajo de la sección inferior. Así, la escena reproducida en los relieves de estuco se complementaba con la corriente de agua del canal para generar una imagen muy parecida a la de la Estela 23 de Izapa, logrando ubicar la acción entre dos espacios cosmológicos, el cielo y los cuerpos y corrientes de agua terrestre.

$\mathrm{Al}$ actuar en conjunto con las características y el significado de este particular contexto arquitectónico, la escena representada logra reproducir los grandes ciclos hidrológicos que involucran al cielo, las nubes, la lluvia, Chaahk y los cuerpos y corrientes de agua, fenómenos naturales que son expresados mediante imágenes narrativas de carácter mítico y dirigidas a un gran público espectador.

Al presentarse como el protagonista de la escena, el gobernante manifiesta las características conductuales y los atributos sagrados del dios por medio de la personificación, lo que le permite formar parte activa de las fuerzas naturales que dinamizan el cosmos y protagonizar un episodio mítico específico.

${ }^{26}$ Inmediatamente debajo del friso de Calakmul se abre un espacio abovedado de 2.8 metros de ancho. El interior de esta bóveda de cañón tiene estuco irregular y manos impresas en negativo, imitando de esta forma el interior de una caverna y su arte rupestre (Carrasco Vargas, 2005: 64; García Barrios, 2007: 271). Este detalle evidencia la estrecha relación existente entre el dios Chaahk y los espacios subterráneos —especialmente la cueva_, misma que forma parte de la cosmovisión maya desde el Preclásico hasta la época actual (consultar García Barrios, 2016).

En la Estela 23 de Izapa el espacio inferior está definido por una banda acuática terrestre. 


\section{Discusión: los casos de estudio analizados desde la semiótica de imágenes}

La concepción de que el propósito primario de la imagen es la comunicación se centra en la noción de que cuando ésta se produce, se consume o se contempla, tiene lugar un proceso comunicativo (Sanz Castro, 1998: 73). Bajo esta perspectiva, los monumentos estudiados son viables de ser analizados desde un enfoque de la semiótica de las imágenes; ciencia que según Göran Sonesson (s/f) debe buscar las leyes que gobiernan la representación por vía de imágenes. Estas leyes conforman un sistema de representación que en gran medida depende del contenido de información. Un estudio completo de las imágenes debe encontrar precisamente las correspondencias entre ambas partes.

Para encontrar dichas correspondencias se aplicarán tres categorías analíticas: la de construcción, la de circulación y la de función. La primera categoría se refiere a la estructuración interna de las imágenes en la configuración de un tema. Se ha analizado cómo la carga simbólica de cada elemento constituyente está determinada no sólo por su valor intrínseco, sino por su comportamiento dentro del contexto; en ese sentido, cobra relevancia la interrelación de los elementos, con la cual cada uno adquiere funciones y significados específicos dentro de la escena. Un factor expresivo importante de las imágenes, el efecto de contiguiidad, resulta de la relación presencia/ausencia de los elementos: la presencia de los personajes reales como protagonistas se da por la ausencia de los dioses; a los cuales se alude a través de múltiples referencias gráficas, logrando así la aserción de una equivalencia entre ambos. Factores expresivos como el tamaño de las figuras humanas, su lugar predominante en la composición y las referencias gráficas a las acciones realizadas, responden a la necesidad de mostrar a la figura real como eje de las escenas.

La categoría de circulación depende de los canales de distribución social de las imágenes. La ubicación de los monumentos en la fachada de los edificios y su integración a los espacios de concurrencia masiva y tránsito es un indicador de su carácter público; esta característica condicionó en gran medida la expresión de los contenidos por medio de un lenguaje visual repetitivo, consistente y visible (Kubler, 1969: 48), mismo que se nutre de una cosmovisión compartida por varios grupos sociales, lo que a su vez propicia la efectiva transmisión de los mensajes.

La categoría de función, que resulta de los efectos socialmente intencionados, atañe al mensaje transmitido y a los propósitos del proceso comunicativo. Se reconoce que el mensaje centrado en la identidad y la función social de los gobernantes y antepasados forma parte de las tácticas ideológicas utilizadas en los discursos de legitimación del poder. De esta forma, su carácter sagrado y su rol activo dentro del cosmos posiblemente son conceptos que se generan como respuestas estratégicas a las demandas de ciertos grupos de élite frente a panoramas sociopolíticos específicos (ver Rappaport, 1971: 28-30). 


\section{Consideraciones finales: el mensaje de los monumentos}

El trasfondo de los monumentos que muestran a la figura real como el eje de eventos de relevancia cósmica y procesos míticos es poner de manifiesto la dimensión sagrada de los gobernantes y de los antepasados y expresar su estrecho vínculo con los dioses; pero, sobre todo, los personajes reales emiten un mensaje en el que son mostrados ante su pueblo como los ordenadores y creadores de una nueva configuración del cosmos y con la capacidad de fomentar, controlar y encarnar los fenómenos naturales.

Esta práctica se encuentra expresada en otros formatos escultóricos de orden público, por ejemplo, en las estelas. En un trabajo reciente, Ana García Barrios (2015) ha planteado que los gobernantes que pisan o se sientan sobre el Cocodrilo Venado Estelar en eventos de entronización aluden al episodio mítico de la decapitación de la criatura, a la destrucción del mundo y a la instauración de una nueva estructura del cosmos (ejemplos: Estelas 6, 11, 14, 25 y 33 de Piedras Negras y Estela 32 de Naranjo). Al utilizar este recurso dentro de los discursos de entronización se produce un vínculo entre ambos eventos, logrando de esta forma presentar al gobernante como el regente de un nuevo orden político y cósmico, jugando un rol activo en la perpetuación de la dinámica del cosmos.

Desde el período Preclásico Tardío y durante todo el Clásico los gobernantes y los antepasados mayas adquirieron gradualmente una dimensión sagrada y una serie de atributos sobrehumanos fundamentados en creencias religiosas, en su interacción con las entidades divinas y en su participación en los procesos míticos de generación y renovación del cosmos.

En ese sentido, concuerdo con los planteamientos de Helmke y Kupprat (en prensa) acerca de la adaptación de los mitos a las necesidades de quienes los controlan y repiten; práctica que, como hemos visto, resulta en un proceso de apropiación de una narrativa mitológica por parte de los grupos o los linajes en el poder. De esta forma, la manipulación de creencias míticas constituye una táctica efectiva para la legitimación del poder dentro de sociedades que, como la maya, fundamentan su aparato ideológico en la cosmovisión.

En conclusión, tanto el friso de Balamkú como los relieves de la Gran Acrópolis Central de El Mirador logran expresar claramente estas ideas acerca de la figura real a través de una variada gama de mecanismos y recursos, por lo que deben ser entendidos como la materialización de una ideología imperante y como elementos estratégicos destinados a generar una imagen y una identidad pública de los gobernantes y de los antepasados reales, con miras a justificar el orden social y sustentar así el poder político.

\section{Agradecimientos}

Quiero expresar mi agradecimiento al sistema de Becas CONACYT (CVU/Becario 591803/574792) por el invaluable apoyo económico que me brindó durante mi 
estancia en el Programa de Posgrado en Estudios Mesoamericanos de la UNAM durante el cual realicé esta investigación como parte de mis actividades académicas. Agradezco también los comentarios y sugerencias de Felix Kupprat y de Carlos Morales Aguilar sobre una versión preliminar de este texto; la amable ayuda de Lucia Henderson y Edwin Román para la publicación del material gráfico, y los consejos y señalamientos puntuales de Ana García Barrios y Rogelio Valencia. También reconozco las aportaciones e ideas de Francisca Zalaquett; mucho de lo aquí expuesto surgió en largas horas de plática. Por último, aunque no menos importante, agradezco el apoyo moral de Concepción, Carlos Gómez Corona, Verónica A. Vásquez López, Felix Kupprat, Carlos Morales y Margarita Cossich Vielman.

\section{BIBLIOGRAFÍA}

Acuña, Mary Jane

2007 "Ancient Maya Cosmological Landscapes: Early Classic Mural Painting at Río Azul, Peten, Guatemala”, tesis de Maestría en Artes. EU. The University of Texas at Austin.

Argyle, J. Craig

2010 "Los paneles y rasgos asociados al manejo de agua en la Gran Acrópolis de El Mirador: Operación 610 O”, Investigaciones arqueológicas en la Cuenca Mirador. Informe final de la Temporada 2009, pp. 539-556, R. Hansen, E. Suyuc y H. Mejía (eds.). Guatemala: Informe resguardado por el Departamento de Monumentos Prehispánicos y Coloniales, Dirección General del Patrimonio Cultural y Natural, Ministerio de Cultura y Deportes.

Assman, Jan y John Czaplicka

1995 "Collective Memory and Cultural Identity", New German Critique. Cultural History/Cultural Studies, 65: 125-133. DOI: 10.2307/488538.

Baudez, Claude-François

2004 Una historia de la religión de los antiguos mayas. México: Universidad Nacional Autónoma de México, Instituto de Investigaciones Antropológicas, Centro de Estudios Mexicanos y Centroamericanos.

2005 "En las fauces del monstruo”, Arqueología Mexicana, XII (71): 58-67.

Carrasco Vargas, Ramón

2005 "La montaña sagrada: arquitectura preclásica en Calakmul”, Los mayas. Señores de la creación: los orígenes de la realeza sagrada, pp. 62-66, V. Fields y D. Reents-Budet (eds.). San Sebastián: Editorial Nerea.

Chinchilla Mazariegos, Oswaldo

2011 Imágenes de la mitología maya. Guatemala: Museo Popol Vuh, Universidad Francisco Marroquín. 
Colas, Pierre R.

2003 "K'inich and King. Naming Self and Person among Classic Maya Rulers", Ancient Mesoamerica, 14: 269-283. DOI: 10.1017/S0956536103132117.

2014 "Personal Names: The Creation of Social Status among the Classic Maya", Acta Mesoamericana, vol. 27. A Celebration of the Life and Work of Pierre Robert Colas, pp. 19-60, C. Helmke y F. Sachse (eds.). Munich: Verlag Anton Saurwein.

Doyle, James y Stephen Houston

2012 "A Watery Tableau at El Mirador, Guatemala", Maya Decipherment, < http:// decipherment.wordpress.com/> [Consultada el 11 de abril de 2012].

Fields, Virginia y Dorie Reents-Budet (eds.)

2005 Los mayas. Señores de la creación. Los orígenes de la realeza sagrada. San Sebastián: Editorial Nerea.

García Barrios, Ana

2007 "El dios Chaahk en el Preclásico maya", Los investigadores de la Cultura Maya, 15 (1): 267-278.

2009 "Chaahk, el dios de la lluvia en el período Clásico maya: aspectos religiosos y políticos”, tesis de doctorado en Antropología de América. España: Universidad Complutense de Madrid, Facultad de Geografía e Historia, Departamento de Historia de América II.

2011 "Análisis iconográfico preliminar de fragmentos de las vasijas estilo códice procedentes de Calakmul”, Estudios de Cultura Maya, XXXVII: 65-98. DOI: http://dx.doi.org/10.19130/iifl.ecm.2011.37.14.

2015 "El mito del diluvio en las ceremonias de entronización de los gobernantes mayas. Agentes responsables de la decapitación del saurio y nuevas fundaciones", Estudios de Cultura Maya, XLV: 11-48. DOI: http://dx.doi. org/10.19130/iifl.ecm.2015.45.132.

2016 "Cuevas y montañas sagradas: espacios de legitimación y ritual del dios maya de la lluvia", Cuevas y cenotes mayas. Una mirada multidisciplinaria, pp. 15-56, R. Romero Sandoval (ed.). México: Universidad Nacional Autónoma de México, Instituto de Investigaciones Filológicas, Centro de Estudios Mayas.

García Barrios, Ana, Ana Martín Díaz y Pilar Asensio Ramos

2005 "Los nombres reales del Clásico: lectura e interpretación mitológica”, XVIII Simposio de Investigaciones Arqueológicas en Guatemala, vol. 2, pp. 636-645, J. P. Laporte, B. Arroyo y H. Mejía (eds.). Guatemala: Ministerio de Cultura y Deportes, Instituto de Antropología e Historia, Asociación Tikal y Foundation for the Advacement of Mesoamerican Studies, Inc.

García Barrios, Ana y Rogelio Valencia Rivera

2011 "Relaciones de parentesco en el mito del Dios Viejo y la Señora Dragón en las cerámicas de estilo Códice", Texto, imagen e identidad en la pintura maya prehispánica, pp. 63-87, M. Paxton y H. Lejarazu (eds.). México: Universidad Nacional Autónoma de México, Instituto de Investigaciones Filológicas, Centro de Estudios Mayas. 
García Barrios, Ana y Verónica Vázquez López

2011 "The Weaving of Power: Women's Clothing and Protocol in the Seventh-Century Kingdom of Kaanu'l", Latin American Indian Literatures Journal. A Review of American Indian Texts and Studies, 27 (1): 50-95.

Gronemeyer, Sven

2010 "A Painted Ceramic Vessel from San Miguel Tayasal, El Petén, Guatemala", Mexicon, XXXII: 145-147.

Grube, Nikolai

2002 "Onomástica de los gobernantes mayas", La organización social entre los mayas prehispánicos, coloniales y modernos. Memoria de la Tercera Mesa Redonda de Palenque, tomo 1, pp. 322-353, V. Tiesler, R. Cobos y M. Greene Robertson (eds.). México: Instituto nacional de Antropología e Historia.

2004 “El origen de la dinastía Kaan”, Los cautivos de Dzibanché, pp. 117-132, E. Nalda (ed.). México: Instituto Nacional de Antropología e Historia.

Guernsey, Julia

2002 "Carved in Stone. The Cosmological Narratives of Late Preclassic IzapanStyle Monuments from the Pacific Slope", Heart of Creation. The Mesoamerican World and the Legacy of Linda Schele, pp. 66-82, A. Stone (ed.). The University of Alabama Press.

2004 "Demystifying the Late Preclassic Izapan-Style Stela-Altar 'Cult”, RES: Anthropology and Aesthetics, 45: 99-122.

Hansen, Richard

2012 "La operación 610W. Informe de la Temporada de Campo 2012", Investigaciones Arqueológicas en la Cuenca Mirador. Informe final de la Temporada 2012, pp. 109-117. Guatemala: Informe resguardado por el Departamento de Monumentos Prehispánicos y Coloniales, Dirección General del Patrimonio Cultural y Natural, Ministerio de Cultura y Deportes.

Hansen, Richard, Edgar Suyuc Ley y Héctor Mejía

2011 "Resultados de la temporada de investigaciones 2009. Proyecto Cuenca Mirador”, XXIV Simposio de Investigaciones Arqueológicas en Guatemala, pp. 174191, B. Arroyo, L. Paiz, A. Linares y A. Arroyave (eds.). Guatemala: Museo Nacional de Arqueología y Etnología.

Helmke, Christophe

2012 "Mythological Emblem Glyphs of Ancient Maya Kings", Contributions in New World Archeology, 3: 91-126.

Helmke, Christophe y Felix Kupprat

En prensa "Where Snakes Abound: Supernatural Places of Origin and Founding Myths in the Titles of Classic Maya Kings", Places of Power and Memory in Mesoamerica's Past and Present, Daniel Graña (ed.). Berlin: Ibero-Amerikanisches Institut. 
Hellmuth, Nicholas

1987 Monster und menschen in der Maya-Kunst. Graz: Akademische Druck-u Verlagsanstalt.

1988 "Early Maya Iconography on an Incised Cylindrical Tripod”, Maya Iconography, pp. 152-174, E. Benson y G. Griffin (eds.). New Jersey: University of Princeton Press.

Houston, Stephen y David Stuart

1998 "The Ancient Maya Self: Personhood and Portraiture in the Classic Period", RES: Anthropology and Aesthetics. Pre-Columbian States of Being, 33: 73-101.

Houston, Stephen, David Stuart y Karl Taube

2006 The Memory of Bones. Body, Being, and Experience among the Classic Maya. Austin: University of Texas Press.

Kubler, George

1969 Studies in Classic Maya Iconography. Memoirs of the Connecticut Academy of Arts and Sciences (XVIII). New Haven: Archon Books.

Knub, Julie, Simone Thun y Christophe Helmke

2009 "The Divine Rite of Kings: An Analysis of Classic Maya Impersonation Statements", Acta Mesoamericana 20. The Maya and Their Sacred narratives. Text and Context in Maya Mythologies, pp. 177-195; G. Le Fort, R. Gardiol, S. Matteo y C. Helmke (eds.). Munich: Verlag Anton Saurwein.

Lacadena, Alfonso

2016 "Evolución de las fórmulas reverenciales mayas asociadas a los títulos políticos de rango y cargo desde el período Clásico hasta la época colonial”, conferencia presentada en el X Congreso Internacional de Mayistas, Izamal, Yucatán, 28 de junio de 2016.

López Austin, Alfredo

2006 Los mitos del tlacuache. Caminos de la mitología mesoamericana. México: Universidad Nacional Autónoma de México, Instituto de Investigaciones Antropológicas.

2009 "Ligas entre el mito y el ícono en el pensamiento cosmológico mesoamericano”, Anales de Antropología, 43: 9-50.

2014 "Ícono y mito, su convergencia”, Antologías de la revista Ciencias 3 Calendario, astronomía y cosmovisión. El conocimiento mesoamericano: 158-178.

López Austin, Alfredo y Leonardo López Luján

2009 Monte sagrado-Templo Mayor. México: Instituto Nacional de Antropología e Historia y Universidad Nacional Autónoma de México, Instituto de Investigaciones Antropológicas.

Martin, Simon

1997 "The Painted King List: A Commentary on Codex-style Dynastic Vases", The Maya Vase Book 5, pp. 846-867, J. Kerr y B. Kerr (eds.). New York: Kerr Associates. 
2002 "The Baby Jaguar: An Exploration of its Identity and Origins in Maya Art and Writing”, La organización social entre los mayas. Memoria de la Tercera Mesa Redonda de Palenque I, pp. 51-78, V. Tiesler, R. Cobos y M. G. Robertson (coords.). México: Instituto Nacional de Antropología e Historia y Universidad Autónoma de Yucatán.

2006a "The Old Man of the Maya Universe: Towards an Understanding of God N", documento presentado en $30^{\circ}$ Maya Meetings at Texas, 14-19 de marzo de 2006, University of Texas at Austin.

2006b "Cacao in Ancient Maya Religion. First Fruit of the Maize Tree and Other Tales from the Underworld", Chocolate in Mesoamerica: A Cultural History of Cacao, pp. 154-183, C. McNeill (ed.). Florida: Series Editors, University of Florida Press.

Mayer, Karl Herbert

1995 Maya Monuments: Sculptures of Unknown Provenance. Supplement 4. Graz: Academic Publishers.

Nanay, Bence

2009 "Narrative Pictures", The Journal of Aesthetics and Art Criticism. Special Issue: The Poetics, Aesthetics and Philosophy of Narrative, 61 (1): 119-129.

Newman, Sarah, Stephen Houston, Thomas Garrison y Edwin Román

2015 "Outfitting a King", Temple of the Night Sun. A Royal Tomb at El Diablo, Guatemala, pp. 84-179, S. Houston, S. Newman, E. Román y T. Garrison (coords.). San Francisco: Precolumbia Mesoweb Press.

Polyukhovych, Yuriy

2015 "A Possible Phonetic Substitution for T533 or 'Ajaw Face”, Glyph Dwellers, Report 33.

Polyukhovych, Yuriy y Raphael Tunesi

2012 "An Unprovenanced Mace Head in the Museo de Historia de Tenosique, Tabasco", Mexicon, XXXIV (5): 98-102.

Quenon, Michel y Geneviève Le Fort

1997 "Rebirth and Resurrection in Maize god Iconography", The Maya Vase Book 5, pp. 884-902, J. Kerr y B. Kerr (eds.). New York: Kerr Associates.

Quirarte, Jacinto

1974 "Terrestrial / Celestial Polymorphs as Narrative Frames in the Art of Izapa and Palenque", Primera Mesa Redonda de Palenque. Part I. A Conference on the Art, Iconography, and Dynastic History of Palenque, pp. 129-135, M. G. Robertson (ed.). Pebble Beach: The Robert Louis Stevenson School-Pre-Columbian Art Research.

Rappaport, Roy

1971 "The Sacred in Human Evolution", Annual Review of Ecology and Systematics, 2: 23-44. DOI: 10.1146/annurev.es.02.110171.000323. 
Reents-Budet, Dorie

1989 "Narrative in Classic Maya Art", Word and Image in Maya Culture, pp. 189-197, W. Hanks y D. Rice (eds.). Salt Lake City: University of Utah Press.

1991 “The 'Holmul Dancer' Theme in Maya Art”, Sixth Palenque Round Table, 1986, pp. 217-222, M. G. Roberton y V. M. Fields (eds.). Norman: University of Oklahoma Press.

Salazar Lama, Daniel

2014 "Aj K’an Witz. Montañas, antepasados y escenas de resurrección en el friso de Balamkú, Campeche", tesis de Maestría en Estudios Mesoamericanos. México: Universidad Nacional Autónoma de México, Facultad de Filosofía y Letras e Instituto de Investigaciones Filológicas.

Salazar Lama, Daniel

2015 "Formas de sacralizar a la figura real entre los mayas", Journal de la Société des Américanistes, 101-1 y 2: 11-49. DOI: 10.4000/jsa.14397.

Sanz Castro, Luis

1998 "Iconografía, significado, ideología: problemas y cuestiones en la interpretación actual del arte mayas", Anatomía de una civilización: aproximaciones interdisciplinarias a la cultura maya, pp. 65-85, A. Ciudad Ruiz, M. Fernández Marquínez, J. M. García Campillo, M. Iglesias Ponce de León, A. Lacadena y L. Sanz Castro (coords.). Madrid: Sociedad Española de Estudios Mayas.

Saturno, William

2009 "Centering the Kingdom, Centering the King: Maya Creation and Legitimization at San Bartolo", The Art of Urbanism. How Mesoamerican Kingdoms Represented Themselves in Architecture and Imagery, pp. 111-134, W. Fash y L. López Luján (eds.). Washington: Dumbarton Oaks Research Library and Collection.

Saturno, William, Karl Taube y David Stuart

2005 "Los murales de San Bartolo, El Petén, Guatemala. Parte 1: El mural del norte”, Ancient America, 7: 1-71.

Saturno, William, Heather Hurst y Franco Rossi

2012 "Observaciones preliminares sobre la iconografía de la Acrópolis Los Árboles (12F19), Xultún”, Proyecto Arqueológico Regional San Bartolo-Xultún Informe de resultados de investigaciones de la temporada de campo $N^{\circ} 11$, año 2012, pp. 561574, P. Rivera Castillo y W. Saturno (eds.). Guatemala: Informe resguardado por el Departamento de Monumentos Prehispánicos y Coloniales, Dirección General del Patrimonio Cultural y Natural, Ministerio de Cultura y Deportes.

Sonesson, Göran

S/F "De la estructura a la retórica en la semiótica visual", Biblioteca Virtual Universal, <www.biblioteca.org.ar> [Consultada el 04 de junio de 2015].

Stone, Andrea

1991 "Aspects of Impersonation in Classic Maya Art", Sixth Palenque Round Table, 1986, pp. 194-202, V. Fields (ed.). Norman: University of Oklahoma Press. 
Stone, Andrea y Marc Zender

2011 Reading Maya Art. A Hieroglyphic Guide to Ancient Maya Painting and Sculpture. London: Thames and Hudson.

Stuart, David

1998 "Blood Symbolism in Maya Iconography", Maya Iconography, pp. 175-221, E. Benson y G. Griffin (eds.). New Jersey: Princeton University Press.

Suyuc, Edgar y Richard Hansen

2015 "Investigaciones regionales de la Cuenca Mirador. Los datos de la temporada 2014", Ponencia presentada en el XXIX Simposio de Investigaciones Arqueológicas en Guatemala. Guatemala, 20 de julio de 2015.

Taube, Karl

1995 "The Rainmakers: The Olmec and their Contribution to Mesoamerican Belief and Ritual”, The Olmec World. Ritual and Rulership, pp. 83-103, J. Guthrie (ed.). New Jersey: The Art Museum, Princeton University.

2004 "Flower Mountain: Concepts of Life, Beauty and Paradise among the Classic Maya”, RES: Anthropology and Aesthetics, 45: 69-98.

2005 "Maws of Heaven and Hell: The Symbolism of Centipede and Serpent in Classic Maya Religion", Antropología de la eternidad: La muerte en la cultura maya, pp. 405-442, A. Ciudad Ruiz, Mario. Ruz y M. Iglesias (eds.). México: Sociedad Española de Estudios Mayas y Universidad Nacional Autónoma de México.

2009 "The Maya Maize God and the Mythic Origins of Dance", The Maya and their Sacred Narratives: Text and Context in Maya Mythologies, pp. 41-52, G. Le Fort, R. Gardiol, S. Matteo y C. Helmke (eds.). Munich: Markt Schwaben, Verlag Anton Saurwein.

Taube, Karl y Stephen Houston

2015 "Masks and Iconography", Temple of the Night Sun. A Royal Tomb at El Diablo, Guatemala, pp. 208-229, S. Houston, S. Newman, E. Román y T. Garrison (coords.). San Francisco: Precolumbia Mesoweb Press.

Taube, Karl, William Saturno, David Stuart y Heather Hurst

2010 "Los murales de San Bartolo, El Petén, Guatemala, parte 2: El mural poniente”, Ancient America, 10: 1-111.

Valdés, Juan Antonio

1989 "El Grupo H de Uaxactún: evidencias de un centro de poder durante el Preclásico", Memorias del II Coloquio Internacional de Mayistas, tomo 1, pp. 603-624. México: Universidad Nacional Autónoma de México, Instituto de Investigaciones Filológicas, Centro de Estudios Mayas.

Valencia Rivera, Rogelio y Ana García Barrios

2010 "Rituales de invocación al dios K'awiil", El ritual en el mundo maya: de lo público a lo privado, pp. 235-262, A. Ciudad Ruiz, M. J. Ponce de León y M. Soroche Cuerva (eds.). Madrid: Sociedad Española de Estudios Mayas, Grupo de Investigación Andalucía-América, Patrimonio Cultural y Relaciones 
Artísticas y Universidad nacional Autónoma de México, Centro Peninsular en Humanidades y Ciencias Sociales.

Valencia Rivera, Rogelio y Hugo García Capistrán

2013 "In the Place of the Mist: Analysis of a Maya Myth from a Mesoamerican Perspective", Acta Mesoamericana, vol. 26. The Maya in a Mesoamerican Context: Comparative Approaches to Maya Studies. Proceedings of the 16th European Maya Conference, pp. 35-50, J. Nielsen y C. Helmke (eds.). Múnich: Markt Schwaben, Verlag Anton Saurwein.

Velásquez García, Erik

2009 "Los vasos de la entidad política de 'IK: Una aproximación histórico-artística. Estudio sobre las entidades anímicas y el lenguaje gestual y corporal en el arte maya Clásico", tesis de doctorado en Historia del Arte. México: Universidad Nacional Autónoma de México, Instituto de Investigaciones Estéticas.

Wichmann, Soren y Jesper Nielsen

En prensa "Sequential Text-Image Pairing among the Classic Maya", The Visual Narrative Reader, N. Cohn (ed.). London. 